\title{
Treatment of Spontaneous Subarachnoid Hemorrhage and Self-Reported Neuropsychological Performance at 6 Months - Results of a Prospective Clinical Pilot Study on Good-Grade Patients
}

\author{
Elisabeth BRÜNDL ${ }^{1}$, Petra SCHÖDEL ${ }^{1}$, Sylvia BELE ${ }^{1}$, Martin PROESCHOLDT ${ }^{1}$, Judith SCHEITZACH ${ }^{1}$, \\ Florian ZEMAN ${ }^{2}$, Alexander BRAWANSKI ${ }^{1}$, Karl-Michael SCHEBESCH ${ }^{1}$ \\ ${ }^{1}$ University Medical Center Regensburg, Department of Neurosurgery, Regensburg, Germany \\ 2University Medical Center Regensburg, Center for Clinical Studies, Regensburg, Germany \\ This study was presented in EANS 2017 meeting in Venice, Italy.
}

\section{ABSTRACT}

AIM: Limited focus has been placed on neuropsychological patient profiles after spontaneous subarachnoid hemorrhage (sSAH). We conducted a prospective controlled study in good-grade SSAH patients to evaluate the time course of treatment-specific differences in cognitive processing after SSAH.

MATERIAL and METHODS: Twenty-six consecutive SSAH patients were enrolled (drop out $n=5$ ). Nine patients received endovascular aneurysm occlusion (EV), 6 patients were treated microsurgically (MS), and 6 patients with perimesencephalic SAH (pSAH) underwent standardized intensive medical care. No patient experienced serious vasospasm-related ischemic or hemorrhagic complications. All patients were subjected to neuropsychological self-report assessment (36-Item Short Form Health Survey and ICD-10-Symptom-Rating questionnaire) subacutely (day $11-35$ ) after the onset of bleeding ( $\mathrm{t}_{1}$ ) and at the 6-month follow-up (FU; $\left.\mathrm{t}_{2}\right)$.

RESULTS: From $t_{1}$ to $t_{2}, M S$ and EV patients significantly improved in physical functioning (Pfi; $p=.001$ each) and the physical component summary ( $p=.010$ vs. $p=.015$ ). Bodily pain (Pain; $M S p=.034$ ) and general health perceptions ( $E V p=.014)$ significantly improved, and nutrition disorder (EV $p=.008$ ) worsened. At FU, MS patients reported significantly better Pfi (vs. EV p=.046), less Pain (vs. EV p=.040), and more depression (vs. pSAH p=.035). Group-rate analyses of test differences showed a significant alleviation in nutrition disorder in MS (vs. EV p=.009).

CONCLUSION: All sSAH groups reported a significant deterioration in health. Though both MS and EV patients, improved in several physical items over time, our data suggest a better short-term Pfi, less Pain and improved nutrition disorder in surgically treated patients. pSAH patients performed significantly better in various aspects of physical and psychological functioning than patients with aneurysmal SAH.

KEYWORDS: Clip, Cognitive impairment, Coil, Neuropsychological outcome, Subarachnoid hemorrhage 


\section{INTRODUCTION}

W ith a peak age of incidence between 40 and 60 years (6), spontaneous subarachnoid hemorrhage (sSAH) predominantly affects relatively young patients in their most productive years with major responsibilities regarding their social and active family lives and their professional career. Experiencing an aneurysmal SAH (aSAH) or nonaneurysmal SSAH represents a sudden and life-threatening event with immediate and high mortality and significant longterm morbidity $(15,63)$. Both those affected and their relatives suffer from the sequelae of the hemorrhage $(15,39)$. Data on functional outcome in population-based SSAH studies are scarce. Regained independence is estimated at $55 \%$, while $19 \%$ remain dependent, and $26 \%$ die (75). With increasing advances in neurointensive care and modern management concepts, the survival rates have improved (75), and the patient's long-term outcome is of paramount importance (62). Besides neurological dysfunction, neuropsychological impairment accounts for the primary causes of disability and reduced quality of life (QOL) in the mid- and long-term after SAH $(3,23,38,43,48,56,69,85,88,114)$. Gross neurological outcome measures like the Glasgow Outcome Scale (GOS)(50) or the modified Ranking Scale (mRS)(92), which are commonly applied in clinical SAH trials, are insufficiently sensitive (43) and may falsely certify a favorable outcome, whereas the subtle but serious cognitive and real-world deficits that accompany sSAH often go undetected $(3,31,43,61,68,83,97)$. Since the late 1980s, the focus of clinical SAH research has increasingly shifted to neuropsychological outcome evaluation to identify patients who will benefit from individualized patient management strategies concerning cognitive and vocational rehabilitation programs, social re-integration and modified medical treatment. Up to $50 \%$ of SAH survivors suffer from cognitive impairment, disabling for years $(3,38,43,56,69)$, with a negative effect on health-related QOL and the ability to work or live independently $(2,10,44,57,72,81,84,107,113,114)$.

Since the publication of the International Subarachnoid Aneurysm Trial (ISAT)(73,74) on good-grade aSAH patients, there has been a widely accepted paradigm shift toward a "coilfirst policy"(60). Given the study biases, there is an ongoing controversy in the literature, whether $(7,25,28,34,91,105)$ or not $(7,29,55,91,99,103)$ coiling is preferable over surgical clipping with regard to a favorable functional and cognitive outcome. To date, only $13 \mathrm{SAH}$ studies $(7,24,26,28,29,34,55$, $58,59,89,91,99,112)$ have directly compared the effects of clipping and coiling on cognitive outcome, and, from those, merely two research groups $(29,55)$ provided information on the time course of neurobehavioral impairment after aSAH. Due to the limited number of studies available addressing this issue, no final conclusion can yet be drawn. In the present prospective controlled study, we evaluated the impact of the respective treatment modality after SSAH on self-reported neuropsychological outcome, defined by the 36-Item Short Form Health Survey (SF-36) and the ICD-10-SymptomRating questionnaire (ISR). For this purpose, all patients with good-grade SSAH were subjected to the standardized neuropsychological self-assessment in the subacute interval and 6 months after microsurgical clipping and endovascular aneurysm repair. Patients with non-aneurysmal perimesencephalic SAH (pSAH) served as control.

\section{MATERIAL and METHODS}

The clinical database and the study protocol were approved by the local institutional Ethics Committee (14-101-0010).

\section{Patient Population}

Prospectively, 26 consecutive patients with acute nontraumatic, aneurysmal and non-aneurysmal sSAH in a prognostically favorable neurological condition were enrolled in this single center trial at our University hospital between February 2013 and May 2016.

\section{Study Selection Criteria}

We selectively included: 1) German native speakers of both sexes, 2) aged 18 to 75 years after, 3) provision of written informed consent. The recruited patients presented 4) with a nontraumatic $\mathrm{SSAH}$, either with an angiography confirmed etiology of an intracranial aneurysm in the anterior or posterior circulation (aSAH), or with a pSAH, and 5) accordingly underwent microsurgical (MS group) or endovascular (EV group) aneurysm occlusion and standardized intensive care unit (ICU) treatment (pSAH group). 6) Each patient was admitted to hospital within 48 hours of ictus in prognostically favorable, good to moderate neurological condition, i.e. Hunt and Hess $(\mathrm{HH})$ score(41) 1 to 4 and initial Glasgow Coma Scale $(G C S) \geq 9,8)$ without any pretreatment cognitive impairment. 7) Within the first 72 hours after the onset of $\mathrm{SAH}$, all patients received an external ventricular drain (EVD) due to acute occlusive hydrocephalus diagnosed by our neuroradiologists. Exclusion criteria were; 1) preceding neurosurgical or neurovascular procedures, 2) previous history of intracranial disorders including repeated or delayed $\mathrm{SAH}$, trauma, or known unruptured intracranial aneurysm (UIA), 3) previous psychiatric history or neurodegenerative diseases, 4) severe autoimmune or systemic diseases, 5) presence of a (giant) aneurysm causing mass effect, or 6 ) severe post-procedural complications like intracranial bleeding after aneurysm treatment or clinically symptomatic cerebral ischemia.

At hospital admission, the patients were graded according to the GCS (11-15 was considered good, 6-10 moderate), the $\mathrm{HH}$ score, the World Federation of Neurosurgical Societies' (WFNS) score $(1,109)$, and the Fisher score (FS)(27). The clinical database comprised all demographic variables, co-morbidities, non-/invasive procedures, complications, outcome grading (GOS(50) and mRS(92)), and a comprehensive pharmacological screening (at discharge and at the 6 month-follow-up (FU)). All patients were examined by cerebral computed tomography (CT) scan and by digital subtraction angiography (DSA) and treated according to our ICU standard operating protocol (51). Each pSAH was confirmed by a magnetic resonance imaging (MRI) of the craniocervical junction to rule out a verifiable bleeding source. Transcranial Doppler ultrasound (TCD) examinations (118) were conducted daily. FU angiography was scheduled after MS during the hospitalization and 6 months after EV. In each pSAH patient, our 
neuroradiologists decided on the timing and number of DSA controls individually on a patient-to-patient basis, depending on the initial DSA findings.

\section{Therapeutic Procedures}

In the aSAH patients group, the neurosurgeons and neuroradiologists decided on the treatment modality after interdisciplinary consent. Our standardized surgical and endovascular procedure protocols are described elsewhere (17). Considering the general trend toward "coil-first policy", our University Medical Center has an annual volume of 80 patients undergoing clipping for both ruptured and unruptured aneurysms.

\section{Neuropsychological Self-Report Assessment}

All patients completed the German version of the SF-36 $(20,116)$, and the ISR $(110)$ in the subacute phase after the onset of bleeding (between day 11 to 35 after SAH; $t_{1}$ ) and in the short-term (chronic phase) at 6 month-FU $\left(t_{2}\right)$. The scores were compared with published normative data, the ISR with a German standard population ( $\mathrm{n}=2512)$, and the SF-36 with both a reference population from Germany $(n=2914)$ and a population norm from the US health survey $(n=2474)$, to make our results comparable with future data. Outcome evaluation was conducted in a single session in a noise-free setting by having the participants complete both surveys, as an inpatient at $t_{1}$ and as an outpatient at $t_{2}$, respectively. No effects of fatigue were apparent. FU assessment additionally comprised a neurological examination and a semi-structured interview, including the patient's subjective health status, the current medication, and the employment status. The interview is a non-standardized method and serves as description of the whole sample. A comparison of the interview results between the groups would neither be methodologically correct nor reasonable, taking the small sample sizes into account.

\section{SF-36}

The SF-36 is a 36-item generic general health questionnaire that yields scores on eight health subscales relating to physical health (physical functioning (Pfi), role limitations due to physical health problems (Rolph), bodily pain (Pain), general health perceptions (Ghp)) and psychological health (vitality (Vital), social functioning (Social), role limitations because of emotional problems (Rolem), and general mental health (Mhi)). These eight subscales can be summarized in a corresponding physical component summary (PCS) and a mental component summary (MCS). The SF-36 also includes a single item that provides an indication of perceived change in health (health transition item, Rawhtran). Each item is scored on a 0 to 100 range and a high score defines a more favorable health state. Items in the same scale are averaged together to create the 8 scale scores $(20,116)$.

\section{ISR}

The ISR aims at a comprehensive evaluation of the severity of psychological disorders. The ISR 2.0 comprises 29 items and six syndrome scales: depression, anxiety, obsessive/compulsive disorders, somatoform disorders, eating disorders, and a supplementary scale, which covers a variety of syndromes (including concentration, suicidality, sleep, appetite, obliviousness, flash backs, problems with activities of daily living, feelings of displacement and alienation, non-organic sexual dysfunction, amongst others), as well as a total score. Each syndrome scale ranges from a minimum of 0 (best performance) to a maximum of 4 points with higher scores indicating a more severe symptom burden. Cut-off values for each syndrome scale grade the degree of severity of symptoms in "suspected", "mild", "moderate", and "severe" (110).

\section{Statistical Analysis}

Continuous data and neuropsychological test results are presented as mean \pm standard deviation (SD) and range (minmax); categorical data as frequency counts. Changes over time within each group were analyzed by using a paired t-test. Differences between groups at post-interventional assessment were analyzed by using an analysis of variance (ANOVA) followed by Fisher's LSD post-hoc pairwise comparisons. A p-value $<.05$ was considered as statistically significant. Statistical analysis was conducted according to SPSS procedures (version 23.0; SPSS, Inc., Chicago, IL, USA).

\section{- RESULTS}

\section{Clinical and Radiological Characteristics and Comparability of the Study Groups}

Five of the 26 patients were excluded from the analysis, since they did not fulfill the selection criteria (lost during FU: $n=3$; incomplete answered questionnaires: $n=1$; postsurgical bihemispheric chronic subdural hematoma requiring revision and epilepsy: $n=1$ ). The baseline characteristics of the 21 enrolled patients are presented in Table I. Intergroup comparisons did not reach any statistical significance.

\section{Treatment Modalities and Results}

Treatment was given either microsurgically via a pterional craniotomy and clipping (MS $n=6$ ) or interventionally ( $E V n=9$ : coil $n=5$, stent-assisted coil $n=2$; balloon-assisted coil $n=1$; flow diverter $n=1$ ). Periprocedurally, no aneurysm ruptured, and no patient required procedure-related blood transfusion. As blood loss during skin incision and microsurgical preparation did not exceed normal volumes, its contribution to post-treatment cognitive performance is negligible. Aneurysm characteristics and intraprocedural findings are shown in Table II. Intergroup comparisons yielded no significant differences except for more middle cerebral artery (MCA) aneurysms in the MS group $(p=.022)$, an unsurprisingly longer duration of MS vs. EV ( $p=.004)$, and a longer time on mechanical ventilatory support in the EV group compared to the pSAH group (EV vs. pSAH p=.0496; $E V$ vs. $M S p=.864$, MS vs. $p S A H$ $\mathrm{p}=.065$ ). This is predominantly due to the fact that the pSAH patients, not experiencing major complications, received general anesthesia for diagnostic DSA only.

\section{Postoperative Course and Short-Term Outcome}

Descriptive statistics are presented in Table III. Intergroup comparisons revealed no significant differences except for 
more intake of antiplatelets at $t_{1}$ in favor of the EV group $(p=.016)$. Procedure-related complications recorded were transient thromboembolic events requiring immediate embolectomy and lysis $(E V n=2)$, intraluminal coil dislocation without thromboembolic event ( $E V \mathrm{n}=1)$, and a dissection of the femoral communicating artery ( $E V n=2, M S n=1$ ). Postprocedurally, none of these patients presented with a new ND. No patient developed CV-related stroke and no patient required decompressive craniectomy.

At discharge, 20/21 patients had no ND. In all patients, functional outcome was stable or even improved during the 6 month-FU. At $t_{2}, 17 / 21$ patients were asymptomatic or had mild symptoms such as recurrent headache (EV $n=4, p S A H n=1)$, fatigue, poor concentration ( $E V n=5, p S A H n=2$ ), subjective memory impairment ( $M S n=1, E V n=4, p S A H n=2)$, dizziness, and depressed mood (MS $n=1, E V n=1)$. The remainder (4/21) presented with confusion ( $M S n=1$ ), dysesthesia, dysarthria, and dysdiadochokinesia $(E V n=3)$. Until FU, no late rebleeding and no mortality have occurred.

\section{Neuropsychological Assessment}

The time points of testing (Table III) did not differ significantly between the groups $\left(t_{1} p=.433 ; t_{2} p=.999\right)$.

Intragroup Comparisons: From $t_{1}$ to $t_{2}$, all groups experienced a significant deterioration in the health transition item (Rawhtran; MS $p=.031$, EV $p=.038$, pSAH $p=.040$ ). MS patients showed significant improvement in physical functioning (Pfi; $p=.001$ ), bodily pain (Pain; $p=.034$ ), and in the physical component summary (PCS; $p=.010$ ). The EV group significantly improved in Pfi $(p=.001)$, general health perceptions (Ghp; $p=.014$ ), and the PCS $(p=.015)$, but deteriorated in nutrition disorder $(p=.008)$.

Intergroup Comparisons: In several subscales of the ISR and the SF-36, our cohort performed significantly worse than the particular population norms, especially at $\mathrm{t}_{1}$ (Figures 2A, B and Figures $4 A, B)$. At $t_{2}$, EV patients still performed significantly worse in $\mathrm{Pfi}$, role limitations due to physical health problems (Rolph), general mental health (Mhi), depression, compulsiveobsessive syndrome, in the ISR total score, and, together with MS patients, in vitality (Vital) compared to healthy controls. Test score comparisons at $t_{1}$ revealed significantly poorer scores in nutrition disorder for the MS than for the EV group $(p=.035)$ and worse Vital $(p=.006)$ for the MS than for the pSAH group. Compared to the pSAH group, EV patients performed significantly worse in the ISR supplementary items score $(p=.024)$, in Pfi $(p=.045)$, and in social functioning (Social; $\mathrm{p}=.046)$ at $\mathrm{t}_{1}$. In the test score comparisons at 6 month-FU, MS patients yielded significantly better Pfi $(p=.046)$ and less Pain $(p=.040)$ than the EV group, but reported more depression $(p=.035)$ than the $p S A H$ group. Compared to the $p S A H$ group, EV patients had a significantly worse ISR total score $(p=.024)$, more depression $(p=.016)$, a worse ISR supplementary items score $(p=.018)$, more Pain $(p=.044)$, and worse Social $(p=.020)$ at $t_{2}$. Group-rate analyses of test differences $t_{2}-t_{1}$ showed a significant alleviation in nutrition disorder in the MS group compared to the EV group $(p=.009)$. Details can be gleaned from Tables IV, V and Figures 1A-C; 2A, B; 3A-C; 4A, B.
Table I: Demographical and Clinical Patient Characteristics

\begin{tabular}{lccc}
\hline \multirow{2}{*}{$\begin{array}{l}\text { Clinical features and } \\
\text { patient characteristics }\end{array}$} & \multicolumn{4}{c}{ Study population } \\
\cline { 2 - 4 } Number of patients [n] & 6 & EV & pSAH \\
\hline Male to female ratio & $2: 4$ & $3: 6$ & $3: 3$ \\
\hline Age [years], mean \pm SD & $42.0 \pm 13.2$ & $50.1 \pm 9.3$ & $59.8 \pm 7.4$ \\
\hline (range) & $(27-61)$ & $(30-59)$ & $(53-72)$ \\
\hline Co-morbidities & & & \\
\hline Arterial hypertension [n] & 3 & 5 & 4 \\
Nicotine abuse [n] & 3 & 2 & 2 \\
Hypothyroidism [n] & 2 & 2 & 0 \\
Cardiac disorders [n] & 1 & 3 & 0 \\
Adiposity [n] & 1 & 1 & 0 \\
Diabetes mellitus [n] & 0 & 0 & 1 \\
Migraine [n] & 0 & 0 & 1 \\
Restrictive ventilation & 1 & 0 & 0 \\
disorder [n] & & & \\
\hline
\end{tabular}

\section{Initial neurological status}

GCS [n]

$15 \quad 1 \quad-5 \quad 4$

$14 \quad 4 \quad 12$

$13-11001$

11100110

$90 \begin{array}{lll}1 & 1 & 0\end{array}$

Hunt and Hess score [n]

\begin{tabular}{llll}
0 & 0 & 0 & 0 \\
I & 2 & 5 & 2 \\
II & 2 & 2 & 4 \\
III & 2 & 1 & 0 \\
IV & 0 & 1 & 0 \\
V & 0 & 0 & 0 \\
\hline
\end{tabular}

WFNS score [n]

\begin{tabular}{llll}
\hline 1 & 1 & 5 & 4 \\
2 & 4 & 2 & 2 \\
3 & 1 & 0 & 0 \\
4 & 0 & 2 & 0 \\
5 & 0 & 0 & 0
\end{tabular}

\section{Fisher score [n]}

\begin{tabular}{llll}
\hline 1 & 0 & 0 & 0 \\
2 & 0 & 0 & 0 \\
3 & 2 & 2 & 2 \\
4 & 4 & 7 & 4
\end{tabular}

EV: endovascular treatment group; GCS: Glasgow Coma Scale; MS: microsurgical clipping group; $\mathbf{p S A H : ~ p e r i m e s e n c e p h a l i c ~ s u b a r a c h n o i d ~}$ hemorrhage group; SD: standard deviation; WFNS: World Federation of Neurosurgical Societies. 
Table II: Aneurysm Characteristics and Procedure Variables

\begin{tabular}{|c|c|c|c|}
\hline Aneurysm characteristics and procedure variables & MS & EV & pSAH \\
\hline \multicolumn{4}{|l|}{ Single aneurysms [n] } \\
\hline ACA & 1 & 0 & - \\
\hline ACoA & 2 & 5 & - \\
\hline Pericallosal artery & 0 & 1 & - \\
\hline PCA & 0 & 0 & - \\
\hline BA & 0 & 2 & - \\
\hline VA & 0 & 1 & - \\
\hline
\end{tabular}

Multiple aneurysms [n]

$\mathrm{ACoA}+\mathrm{MCA}^{\mathrm{b}}$ (unruptured)

ACoA + "bleb" ACA (unruptured)

$\mathrm{MCA}+\mathrm{MCA}^{\mathrm{c}}$ (unruptured)

\begin{tabular}{lll}
0 & 1 & - \\
1 & 0 & - \\
1 & 0 & - \\
\hline
\end{tabular}

Total number of aneurysms [n]

Anterior circulation

Posterior circulation

\begin{tabular}{ccc}
8 & 7 & $1^{\mathrm{a}}$ \\
0 & 3 & - \\
\hline 8 & 10 & $1^{\mathrm{a}}$
\end{tabular}

\section{Side of aneurysms [n]}

Left

Right

$\begin{array}{lll}3 & 2 & 1^{\mathrm{a}} \\ 4 & 2 & -\end{array}$

Side of pterional approach

Dominant-side

Non-dominant side

3

Procedure variables

\begin{tabular}{|c|c|c|c|}
\hline $\begin{array}{l}\text { Latency from onset of the SAH to aneurysm occlusion [d], mean } \pm \mathrm{SD} \\
\text { (range) }\end{array}$ & $\begin{array}{l}0.83 \pm 0.75 \\
(0-2)\end{array}$ & $\begin{array}{l}1.44 \pm 1.42 \\
(0-5)\end{array}$ & - \\
\hline $\begin{array}{l}\text { Temporary parent artery occlusion [min], mean } \pm \text { SD } \\
\text { (range) }\end{array}$ & $\begin{array}{l}3.42 \pm 2.76 \\
\quad(0-7)\end{array}$ & - & - \\
\hline $\begin{array}{l}\text { Duration of aneurysm surgery/intervention [min], mean } \pm \text { SD } \\
\text { (range) }\end{array}$ & $\begin{array}{c}242.33 \pm 24.75^{*} \\
(205-279)\end{array}$ & $\begin{array}{l}136.67 \pm 46.87^{*} \\
(55-200)\end{array}$ & - \\
\hline $\begin{array}{l}\text { Time with mechanical ventilatory support [hours], mean } \pm \text { SD } \\
\text { (range) }\end{array}$ & $\begin{array}{l}116.03 \pm 244.14^{d} \\
(2.17-613.63)\end{array}$ & $\begin{array}{l}117.99 \pm 264.14^{*} d \\
(6.92-808.83)\end{array}$ & $\begin{array}{c}5.82 \pm 6.34^{*} \\
(0-14.83)\end{array}$ \\
\hline
\end{tabular}

Aneurysm occlusion rate at $F U$

Complete [n]

Incomplete [n]

5

1
6

3

a, b, c Unruptured aneurysms were either treated after the study period or were not eligible due to small dome size. ACA: anterior cerebral artery; ACoA: anterior communicating artery; BA: basilar artery; ${ }^{d} 1 \mathrm{MS}$ and $1 \mathrm{EV}$ patient required prolonged mechanical ventilatory support $(613.63 \mathrm{~h}$ vs. 808.83 h) due to compromised pulmonary gas exchange and inadequate waking reaction with intolerance of the intubation tube, consecutive transient peaks of the intracranial pressure and cerebral vasospasm, respectively. Both patients underwent transient tracheotomy for successful weaning from the respirator. d: days; EV: endovascular treatment group; FU: 6-month follow-up; ICA: internal carotid artery; MCA: middle cerebral artery; min: minutes; MS: microsurgical clipping group; PCA: posterior cerebral artery; PCoA: posterior communicating artery; pSAH: perimesencephalic subarachnoid hemorrhage group; SAH: subarachnoid hemorrhage; SD: standard deviation; VA: vertebral artery. ${ }^{*} p$ <.05. 


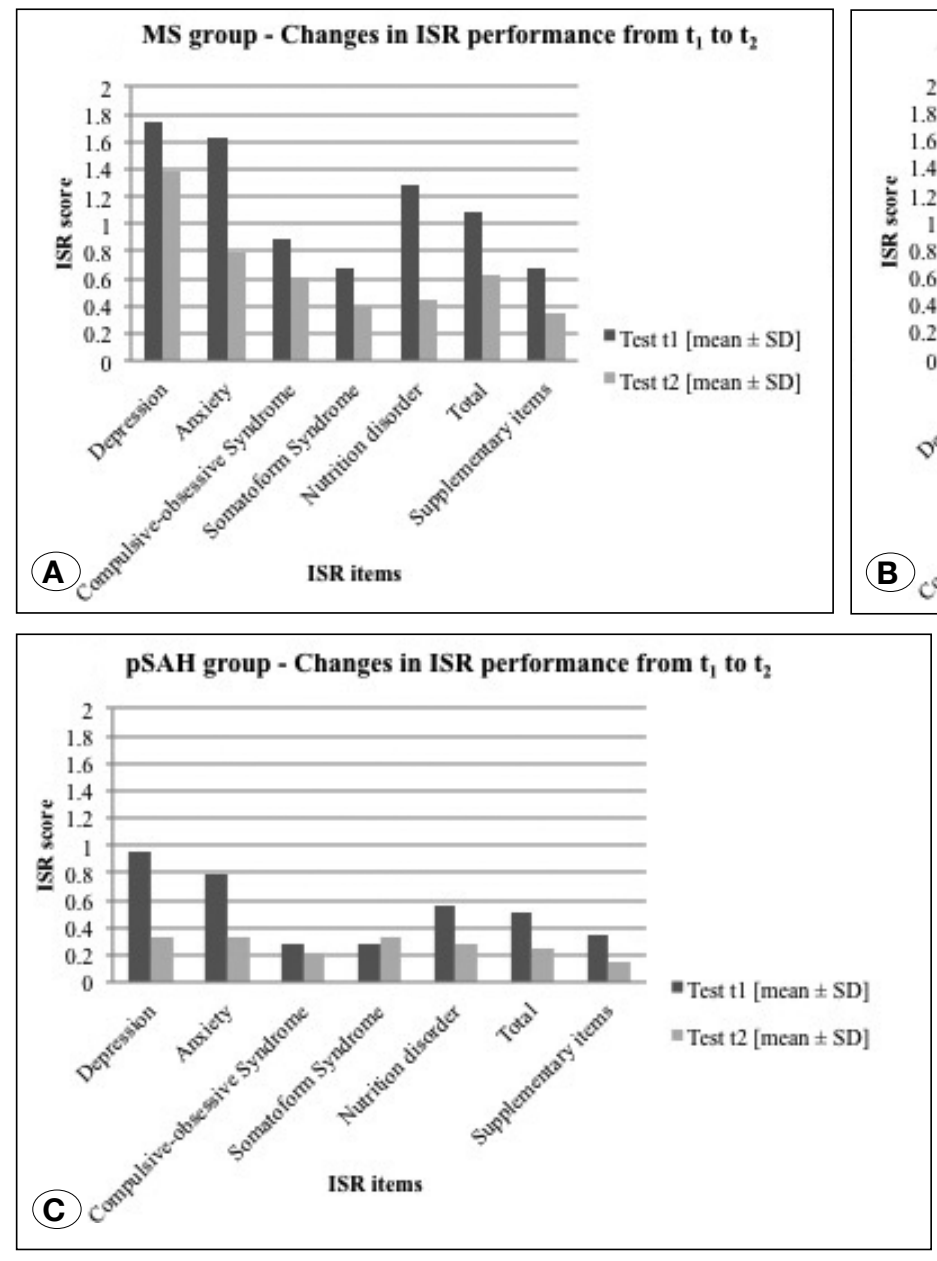

EV group - Changes in ISR performance from $t_{1}$ to $t_{2}$

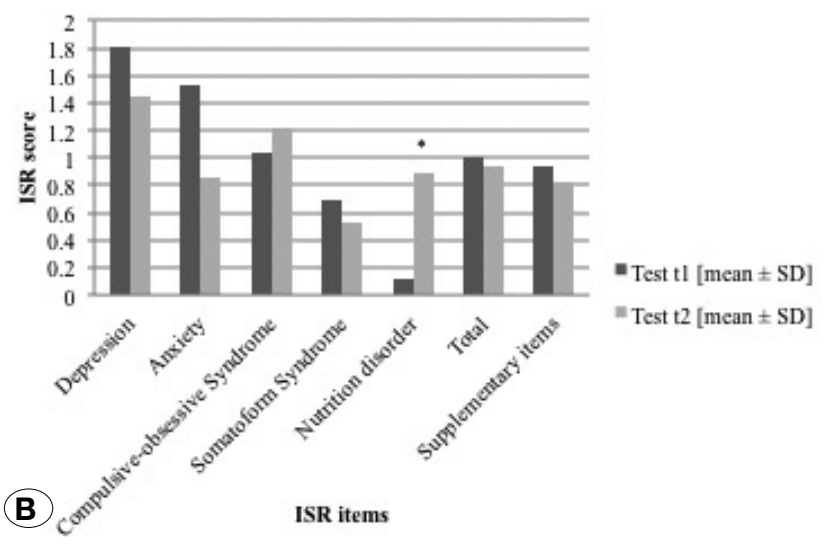

Figure 1: Intragroup comparisons between the subacute assessment $\left(t_{1}\right)$ between days $11-35$ after the onset of spontaneous subarachnoid hemorrhage (sSAH) and evaluation at 6 month-follow-up $\left(\mathrm{t}_{2}\right)$ after $\mathrm{SSAH}$, measured by the ISR. The 7 items of the ISR are shown on the $x$-axis. On the left side the ordinate is scaled metrically. The bar chart represents the two time points of assessment (dark grey for testing at $t_{1}$, light grey for $t_{2}$ ) for $(\mathbf{A})$ the microsurgery (MS) group, (B) for the endovascular (EV) group, and (C) for the perimesencephalic SAH (pSAH) group. ${ }^{*} p<0.05$.

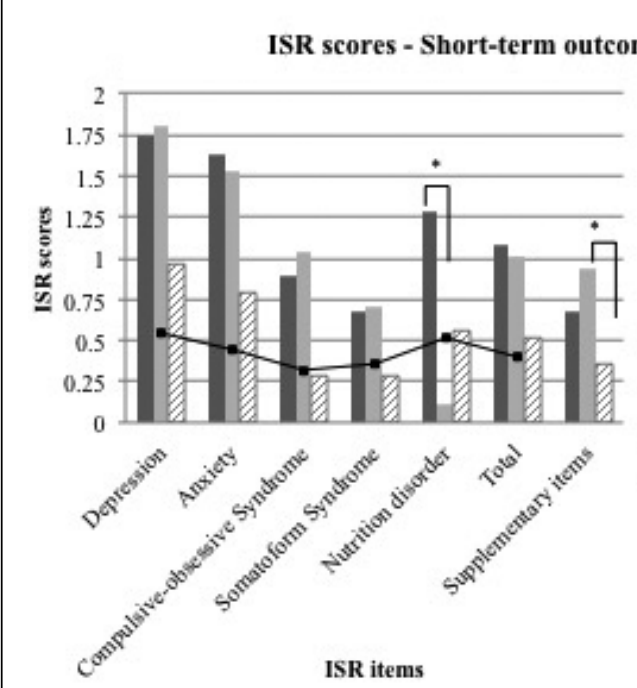

(A)

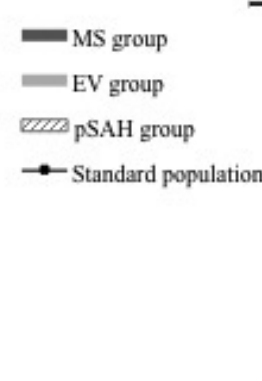

(B)

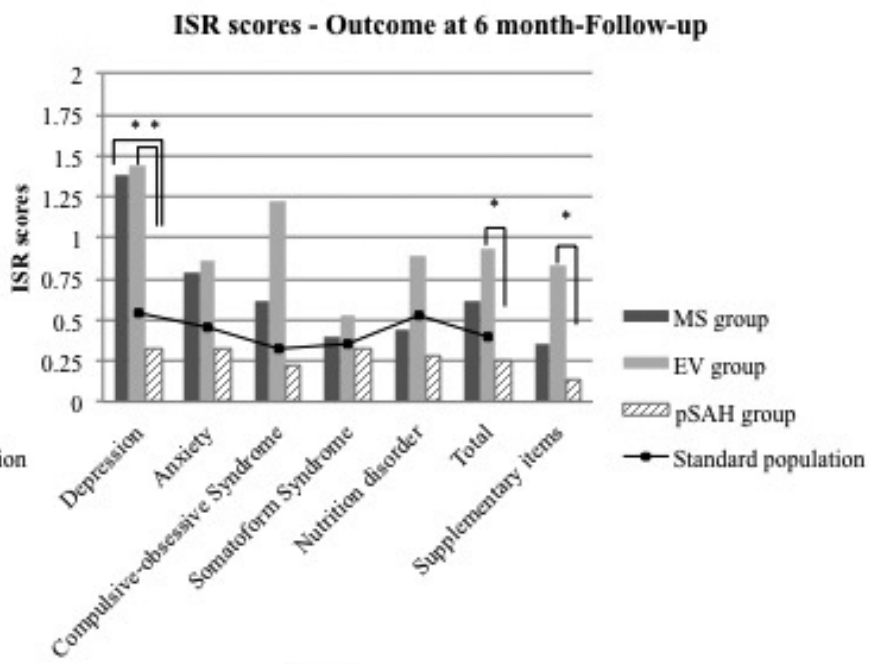

ISR items

Figure 2: Intergroup comparisons between $(\mathbf{A})$ the subacute assessment $\left(t_{1}\right)$ between days $11-35$ after the onset of spontaneous subarachnoid hemorrhage (sSAH) and (B) evaluation at 6 month-follow-up $\left(t_{2}\right)$ after sSAH, measured by the ISR. The 7 items of the ISR are shown on the $\mathrm{x}$-axis. On the left side the ordinate is scaled metrically. The line graph shows the standard population, whereas the bar chart represents the different groups (dark grey for the microsurgery (MS) group, light grey for the endovascular (EV) group, striped bars for the perimesencephalic SAH (pSAH) group). ${ }^{*} \mathrm{p}<0.05$. 


\section{DISCUSSION}

\section{Neuropsychological Outcome and QOL after SSAH with a Focus on Good-Grade SAH Patients}

Our study substantiates that $\mathrm{QOL}$ is considerably impaired in good-grade SAH survivors. As shown in the literature, culture has a considerable effect on neuropsychological tests and, thus, test results cannot be extrapolated from one country to another $(4,98)$. To account for cultural differences, we compared the SF-36 scores not only to the commonly cited normative data from the US health survey but also to a German reference population. For the most part, our SF36 results were comparable between both population norms. Demands on outcome instruments imply the assessment of essential aspects of daily life with accepted rates of validity and reliability, like the currently used ISR and the SF-36. Multiple previous SAH investigations $(39,53,54,101,104,119)$ have used the SF-36, even in poor-grade SAH $(36,104)$, showing an impact on all tested items of the SF-36 $(39,53,101)$. To the best of our knowledge, this is the first trial measuring neuropsychological impairment after SAH by means of the
ISR which is a broadly accepted instrument in psychosomatic disorders and well-established in clinical routine (79). Compared to healthy controls, both the MS and the EV group revealed significantly reduced indices in most SF-36 and ISR subscales, in particular at the early stage of recovery. These differences leveled off at 6 month-FU. Interestingly, however, EV patients still performed significantly worse in Pfi, Rolph, Pain, Vital, Mhi, ISR total score, depression, and compulsiveobsessive syndrome. Given the non-significant intergroup differences between clipped and coiled patients at $t_{1}$, these results may indicate that clipped patients recover at a faster rate than their coiled counterparts, at least in terms of QOL aspects. A caveat to this hypothesis is the small sample size in the present study, and the fact that intergroup comparisons of test differences revealed no significant differences between MS and EV. Only a few prospective SAH studies have assessed the QOL either by semistructured interview $(43,61,82,100)$ or by validated instruments $(39,40,47)$ with a broad variance in the timing of examination ( 2 weeks to 24.5 years), and an even smaller number of authors, like Preiss et al.(90) have considered treatment-specific differences. Analyses of good-
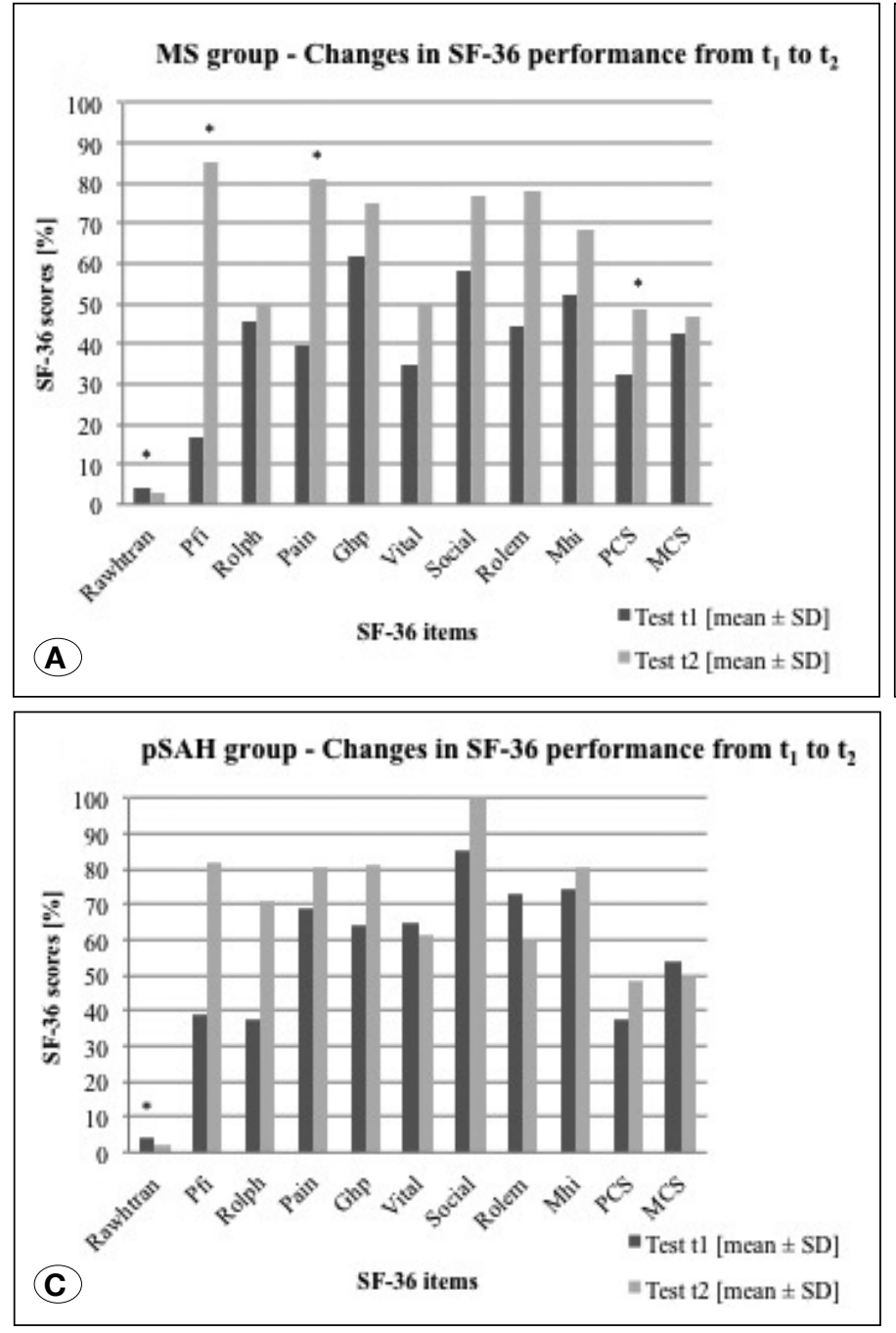

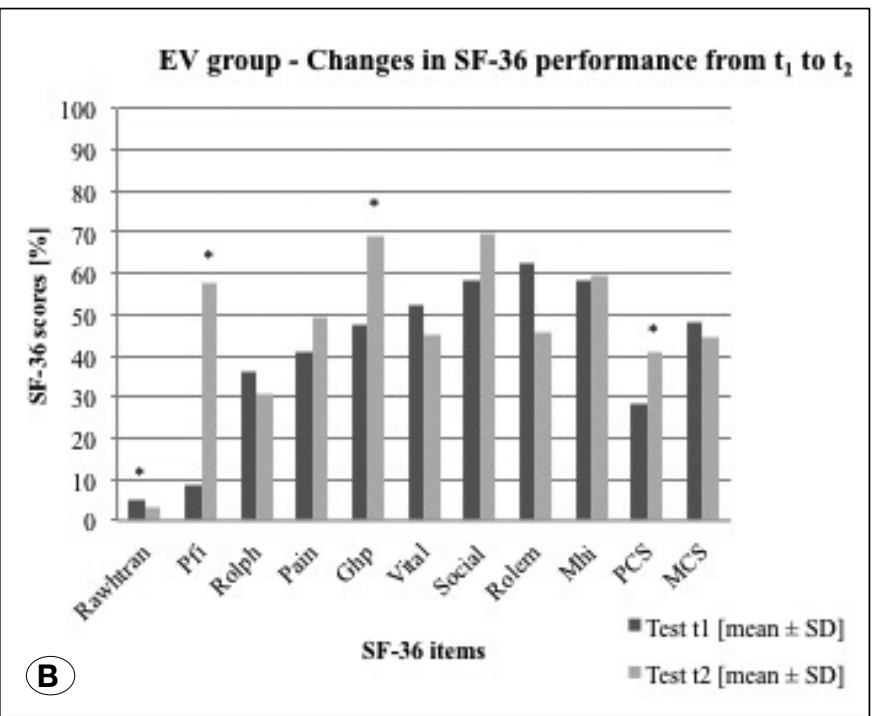

Figure 3: Intragroup comparisons between the subacute assessment $\left(t_{1}\right)$ between days $11-35$ after the onset of spontaneous subarachnoid hemorrhage (sSAH) and evaluation at 6 month-follow-up $\left(t_{2}\right)$ after sSAH, measured by the SF-36. The 8 items of the SF- 36 are shown on the x-axis. On the left side the ordinate is scaled metrically. The bar chart represents the two time points of assessment (dark grey for testing at $t_{1}$, light grey for $t_{2}$ ) for (A) the microsurgery (MS) group, (B) for the endovascular (EV) group, and (C) for the perimesencephalic $\mathrm{SAH}(\mathrm{pSAH})$ group. ${ }^{*} \mathrm{p}<0.05$. 
grade SAH patients by means of the SF-36 revealed divergent data, depending on the time of assessment. At 4 month-FU, a significant reduction in QOL (specifically in Social, Rolem, and Mhi) was observed, followed by a 50 percent improvement of the SF-36 scores at 18 month-FU (39). Only modest deterioration in QOL was reported 4.7 years (101) and 10 years (115) after good-grade SAH. However, even in long-term SAH survivors (107), re-integration difficulties with reduced independence and decreased employment rates have been observed $(22,87,107,117)$.

\section{Impact of the Time of Assessment on Neuropsychological Impairment}

Various factors might modulate the severity and nature of neuropsychological deficits measured in the different SAH studies. One of these variables is the time of testing in relation to the initial insult. In our cohort, both MS and EV patients experienced significant improvement in several physical items within 6 months, while psychological SF-36 items seemed to remain stable in all groups. Interpreting our results with caution due to the small sample size, it might be speculated that physical functioning improves at a faster rate than psychological functioning in good-grade $\mathrm{SAH}$ patients without major ND. The majority of studies $(22,33,39,69,71,86,96)$ have focused on the early stages of recovery after SAH with limited insight into the neurobehavioral long-term consequences $(12,35,44,61,71,82,93,107)$. Neuropsychological deficits (3), predominantly in cognition $(39,69)$, QOL $(40,47,96,115,120)$, mood (114), and fatigue (114), are most common within the first 3 months (86); however, they can persist as long as 24.5 years after aSAH and perhaps longer $(10,94,107)$.
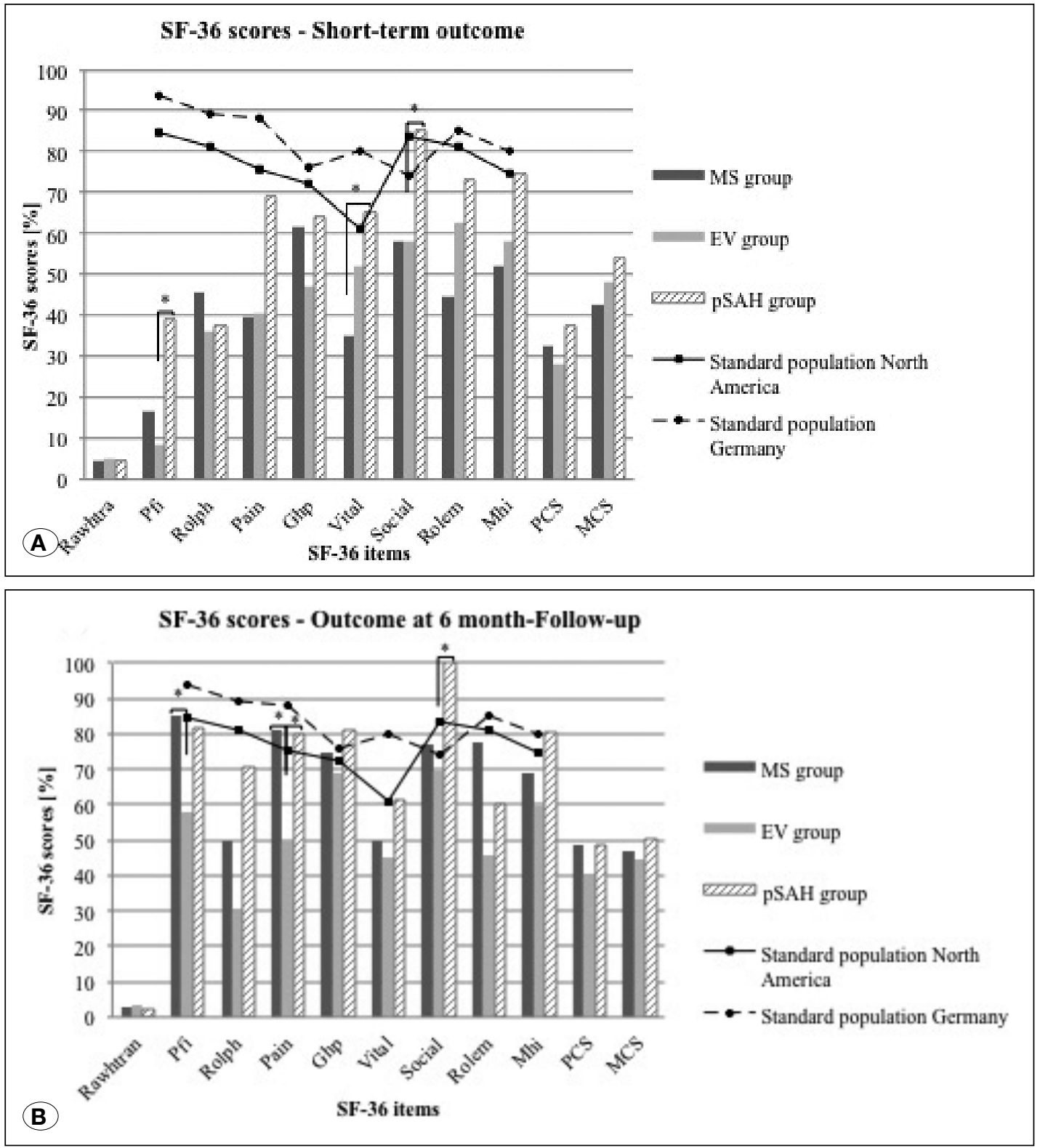

Figure 4: Intergroup comparisons between (A) the subacute assessment $\left(\mathrm{t}_{1}\right)$ between days $11-35$ after the onset of spontaneous subarachnoid hemorrhage (sSAH) and $(B)$ evaluation at 6 month-follow-up $\left(\mathrm{t}_{2}\right)$ after $\mathrm{SSAH}$, measured by the SF-36. The 8 items of the SF-36 are shown on the $x$-axis. On the left side the ordinate is scaled metrically. The line graph shows the standard population (continuous line for the US norm, dashed line for the German norm), whereas the bar chart represents the different groups (dark grey for the microsurgery (MS) group, light grey for the endovascular (EV) group, striped bars for the perimesencephalic SAH (pSAH) group). *p $<0.05$. 
Table III: Clinical Course and Outcome Assessment

\begin{tabular}{|c|c|c|c|}
\hline \multirow{2}{*}{ Clinical Course, Internal Complications and Outcome Assessment } & \multicolumn{3}{|c|}{ Study population } \\
\hline & MS & EV & pSAH \\
\hline \multicolumn{4}{|l|}{ External ventricular drainage } \\
\hline $\begin{array}{l}\text { Implantation after the onset of SAH }[d] \text {, mean } \pm \text { SD } \\
\text { (range) }\end{array}$ & $\begin{array}{l}0.50 \pm 0.55 \\
(0-1)\end{array}$ & $\begin{array}{l}0.44 \pm 0.73 \\
(0-2)\end{array}$ & $\begin{array}{l}0.50 \pm 0.55 \\
(0-1)\end{array}$ \\
\hline $\begin{array}{l}\text { In situ }[\mathrm{d}], \text { mean } \pm \mathrm{SD} \\
\text { (range) }\end{array}$ & $\begin{array}{l}15.83 \pm 4.88 \\
(9-23)\end{array}$ & $\begin{array}{l}15.13 \pm 7.68 \\
(9-30)\end{array}$ & $\begin{array}{c}12.00 \pm 4.95 \\
(5-18)\end{array}$ \\
\hline Replacement [n] & 0 & 2 & $\begin{array}{c}(0-10) \\
1\end{array}$ \\
\hline CSF infection [n] & 1 & 4 & 2 \\
\hline Permanent ventriculoperitoneal shunt placement [n] & 0 & 2 & 2 \\
\hline Implantation after the onset of SAH [d], mean \pm SD & - & $23.50 \pm 0.71$ & $29.50 \pm 6.36$ \\
\hline (range) & - & $(23-24)$ & $(25-34)$ \\
\hline \multicolumn{4}{|l|}{ Cerebral vasospasm [n] } \\
\hline DIND & 1 & 1 & 0 \\
\hline TCD & 6 & 7 & 3 \\
\hline DSA & 0 & 2 & 1 \\
\hline Multimodal neuromonitoring & 1 & 1 & 0 \\
\hline Intraarterial cerebral spasmolysis ${ }^{a}$ & 0 & 2 & 0 \\
\hline
\end{tabular}

Treatment-associated lesions on CT scan [n]

Circumscript ischemia ${ }^{b}$

Brain edema

Bleeding along the EVD entry route

Hygroma

\begin{tabular}{llc}
2 & 2 & 0 \\
3 & 1 & 0 \\
1 & 0 & 1 \\
0 & 0 & $1^{\mathrm{c}}$ \\
\hline
\end{tabular}

Internal complications [n]

Pneumonia

Compromized pulmonary gas exchange

Electrolyte imbalance

SIADH

Diabetes insipidus

ECG alterations, arrhythmia

Hypertensive crisis

Seizure

Beginning multiorgan failure (not requiring dialysis)

Acute pancreatitis

Propofol infusion syndrome

Hypothyroidism

Hyperthermia

Hyperglycemia

Delirium

Disorientation/agitation

$\begin{array}{lll}2 & 2 & 0 \\ 1 & 1 & 0 \\ 3 & 6 & 5 \\ 0 & 0 & 1 \\ 0 & 0 & 1 \\ 1 & 2 & 0 \\ 1 & 4 & 2 \\ 1 & 1 & 0 \\ 0 & 1 & 0 \\ 0 & 1 & 0 \\ 0 & 1 & 0 \\ 0 & 1 & 1 \\ 0 & 1 & 1 \\ 0 & 1 & 1 \\ 1 & 1 & 0 \\ 1 & 1 & 0\end{array}$

\begin{tabular}{|c|c|c|c|}
\hline \multicolumn{4}{|c|}{ Average length of hospital stay [d], mean \pm SD (range) } \\
\hline $\begin{array}{l}\text { On the ICU } \\
\text { (range) }\end{array}$ & $\begin{array}{c}20.17 \pm 6.91 \\
(12-31)\end{array}$ & $\begin{array}{c}20.11 \pm 7.85 \\
\quad(9-35)\end{array}$ & $\begin{array}{c}14.67 \pm 7.92 \\
(7-29)\end{array}$ \\
\hline $\begin{array}{l}\text { Total } \\
\text { (range) }\end{array}$ & $\begin{array}{c}25.17 \pm 4.67 \\
(21-31)\end{array}$ & $\begin{array}{c}28.44 \pm 6.11 \\
(22-40)\end{array}$ & $\begin{array}{c}26.83 \pm 11.05 \\
(14-42)\end{array}$ \\
\hline
\end{tabular}


Table III: Cont.

\begin{tabular}{|c|c|c|c|}
\hline \multirow{2}{*}{ Clinical Course, Internal Complications and Outcome Assessment } & \multicolumn{3}{|c|}{ Study population } \\
\hline & MS & EV & pSAH \\
\hline \multicolumn{4}{|l|}{ Medication at discharge / at FU } \\
\hline Anticonvulsive drugs & $1 / 1$ & $0 / 1$ & $0 / 0$ \\
\hline Benzodiazepines & $0 / 0$ & $1 / 0$ & $0 / 0$ \\
\hline Antidepressants & $0 / 0$ & $3 / 1$ & $1 / 1$ \\
\hline Neuroleptics & $0 / 0$ & $0 / 0$ & $0 / 0$ \\
\hline Opioid & $2 / 0$ & $1 / 1$ & $2 / 0$ \\
\hline Nicotine patches & $0 / 1$ & $0 / 1$ & $0 / 1$ \\
\hline Antihypertensive drugs & $4 / 3$ & $4 / 6$ & $3 / 3$ \\
\hline Thyroid medication & $3 / 3$ & $2 / 2$ & $0 / 0$ \\
\hline Antiplatelet agents & $0 / 0$ & $5^{*} / 3$ & $0 / 0$ \\
\hline No medication & $0 / 2$ & $0 / 1$ & $0 / 2$ \\
\hline
\end{tabular}

\section{Neurological status at discharge / at FU} GOS [n]

\begin{tabular}{|c|c|c|c|}
\hline 5 & $4 / 5$ & $7 / 7$ & $5 / 6$ \\
\hline 4 & $0 / 0$ & $1 / 2$ & $1 / 0$ \\
\hline 3 & $2 / 1$ & $1 / 0$ & $0 / 0$ \\
\hline \multicolumn{4}{|l|}{$\mathrm{RS}$ [n] } \\
\hline 0 & $4 / 2$ & $7 / 3$ & $4 / 5$ \\
\hline 1 & $0 / 3$ & $0 / 3$ & \\
\hline 2 & $1 / 0$ & $1 / 3$ & $0 / 0$ \\
\hline 3 & $0 / 1$ & $0 / 0$ & $0 / 0$ \\
\hline 4 & $1 / 0$ & $1 / 0$ & $0 / 0$ \\
\hline
\end{tabular}

\section{Patients with new neurological deficit [n]}

At discharge

At FU

$\begin{array}{lll}0 & 1 & 0 \\ 1 & 3 & 0\end{array}$

\section{Employment status at FU [n]}

Returned to work

Attending vocational integration programs

On sick leave

Unemployed

Unemployed before and after the onset of SAH

Retired at the onset of SAH

No information provided

1
0
1
1
0
0
3

$\begin{array}{ll}2 & 1 \\ 2 & 0 \\ 3 & 0 \\ 1 & 0 \\ 1 & 0 \\ 0 & 1 \\ 0 & 4\end{array}$

\section{Neuropsychological assessment after the onset of SAH (SF-36 and ISR)}

Subacute phase $\left(t_{1}\right)[d]$, mean $\pm S D$ (range)

$\begin{array}{ccc}15.67 \pm 4.89 & 14.78 \pm 7.34 & 14.67 \pm 3.88 \\ (12-25) & (11-34) & (12-22) \\ & & \\ 186.00 \pm 9.94 & 185.67 \pm 11.32 & 185.83 \pm 16.86 \\ (176-204) & (169-209) & (164-208)\end{array}$

Chronic phase $\left(t_{2}\right)[d]$, mean $\pm S D$ (range)

$(176-204)$

$(169-209)$

(164 - 208)

a Transient placement of transfemoral microcatheters for local intraarterial cerebral spasmolysis ( $n=1$ continuous nimodipine infusion for 3 and 5 days; $n=1$ single shot infusion of milrinone) to reverse severe cerebral vasospasm. ${ }^{b}$ clinically silent ischemia, either in the section of the caudate nucleus, following unintended clipping of the recurrent artery of Heubner, or diffusely in the periventricular white matter; ${ }^{c}$ conservatively treated bi-hemispheric hygromas due to CSF overdrainage via the EVD; CSF: cerebrospinal fluid; CT scan: computerized axial tomography scan; d: days; DIND: delayed ischemic neurological deficit (transient dysarthria and paresthesias); DSA: digital subtraction angiography; ECG: electrocardiogram; EV: endovascular treatment group; EVD: external ventricular drainage; FU: 6-month follow-up; GOS: Glasgow Outcome Scale; ICU: intensive care unit; ISR: ICD-10-Symptom-Rating questionnaire; mRS: modified Rankin Scale; MS: microsurgical clipping group; pSAH: perimesencephalic subarachnoid hemorrhage group; SAH: subarachnoid hemorrhage; SD: standard deviation; SF-36: short form 36-item health survey; SIADH: syndrome of inappropriate antidiuretic hormone secretion; $\boldsymbol{t}_{1}$ : days 11 - 35 after the onset of SAH (subacute phase); $\boldsymbol{t}_{2}: 6$ months after the onset of SAH (chronic phase); TCD: transcranial Doppler ultrasound. ${ }^{*} p<.05$. 


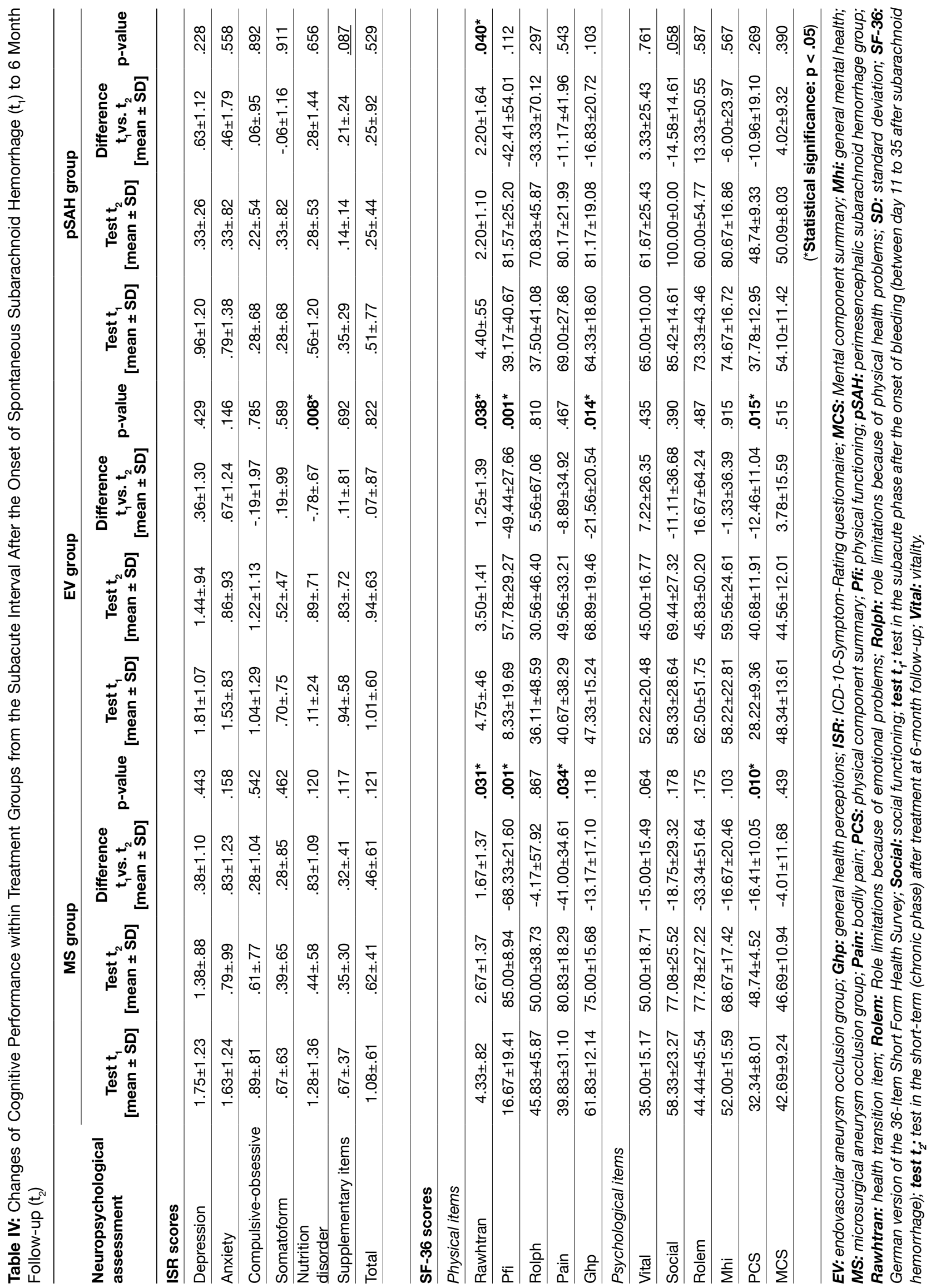




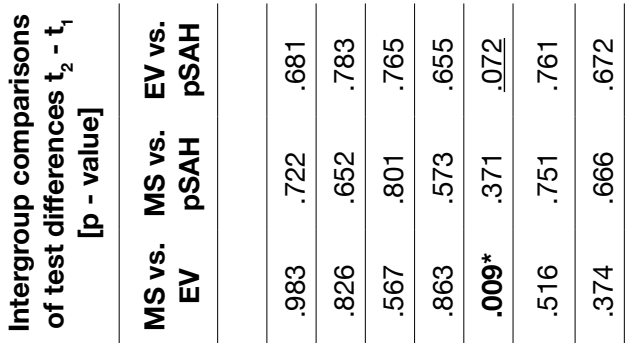

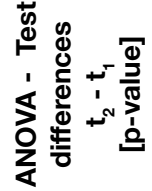

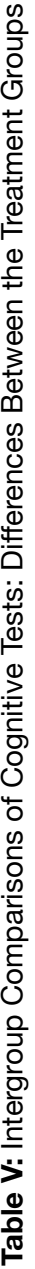

员:

ㄷำ

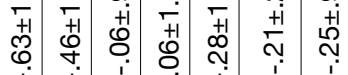

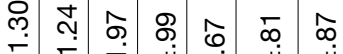

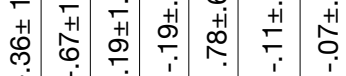

위워

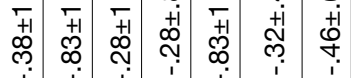

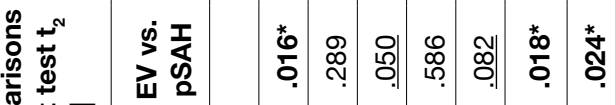

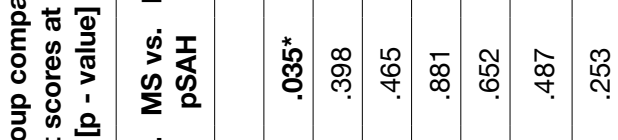

$\frac{10}{20}$ 离

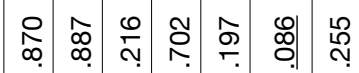

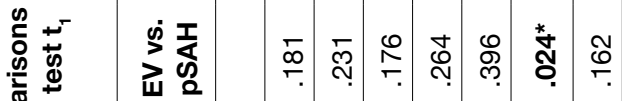

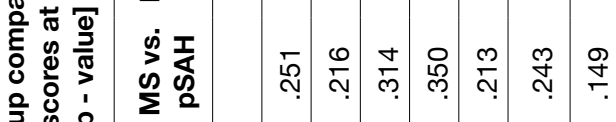

言若急

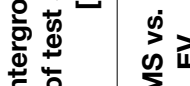

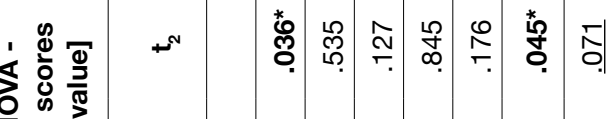
峞 总 㣽

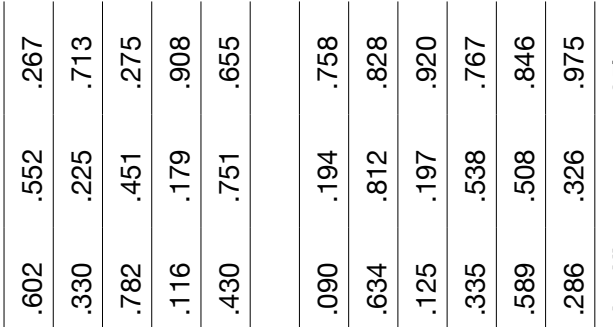

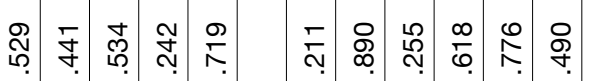

ป

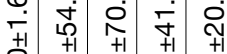

त़े

ง่

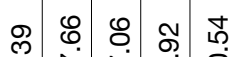

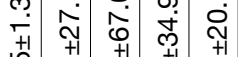

茦

广 gु

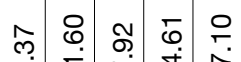

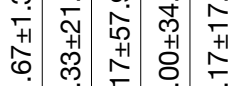

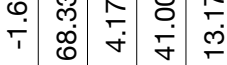

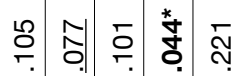

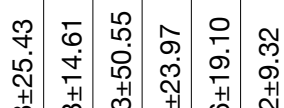

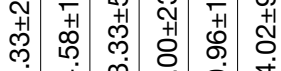

ஸे

办 \&

هi

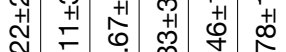

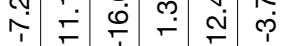

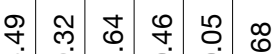

ம)

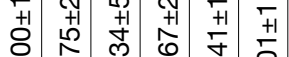

官

商

兽

స్ল̣. ㅎํ:

究

苍

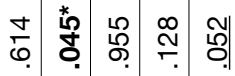

赵

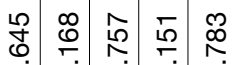

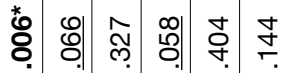

我㤐

\&! :

ஸ़ঙ

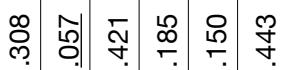

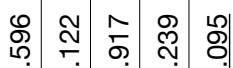

苛 일 总

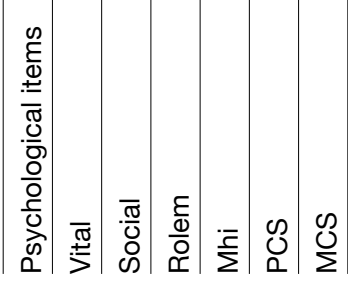

站

万人

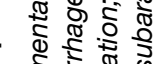

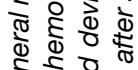

क. 응 웡

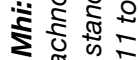

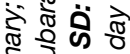

है के

क

\& \&

हैष

0 .

刃․

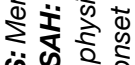

कु

$\sum$ के \&

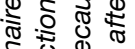

동

을 논

o का

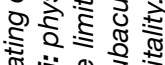

ชิ

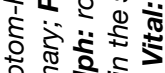

으응

कह है क्ष

की क्ष

的券

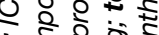

बू. हैं के के

is 응 웅

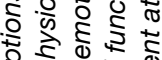

ष्ट

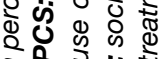

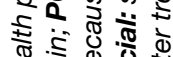
웡 0

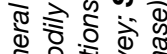

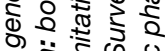

क्षे

잉

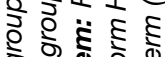

के

흥 웅

ग्रे हैं के

O०

ह ह $\Phi .5$

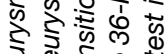

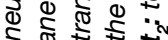

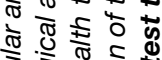

ว

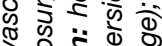

。

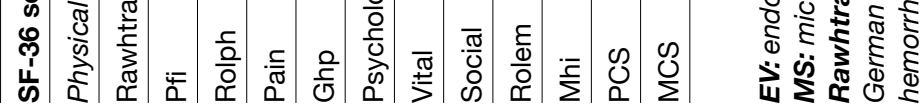

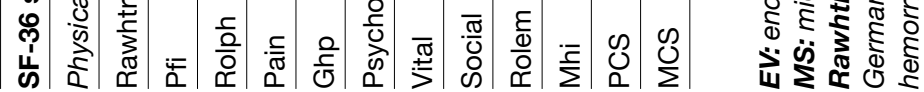


Meta-analyses by Al-Khindi et al. (3), and by Egeto et al.(25) suggest that clipping might be associated with a more favorable cognitive performance in the early stages (i.e. within 6 months after treatment) after SAH and, in the long-term ( $\geq 12$ months post-treatment), a superior cognitive outcome after coiling. This theory equals our results that, at 6 months, MS patients performed significantly better than the EV group. Interestingly, together with others (30), we yielded contrary results (with impaired short-term executive processing in MS patients) when analyzing treatment-associated effects on cognition in patients with anterior circulation UIA (17). So far, only two other SAH studies $(29,55)$, comparing treatment-specific effects on cognition, conducted FU-testing (10 days (29), 3 months (55), 6 months (29), and 12 months (55) post-treatment) and, thus, provide some information on the time course of cognitive changes. The results are consistent with our findings: In both cohorts, both treatment groups were impaired on a wide range of cognitive tests and experienced minor improvements in a few domains during the months following treatment. At medium-length FU (3(55) and 6 months (29)), clipped patients outperformed the coiled patients in the executive, visuospatial and intelligence domains. No intergroup differences emerged at the 12 month-FU. Several previous SAH studies indicated a recovery of neuropsychological functions at different rates $(29,37,55,86,87)$ over time $(13,67,81,86,108)$. Yet, the data from the recent meta-analysis (25) hypothesizes that SAH survivors do not return to pre-existing levels of cognitive functioning after treatment. To date, only Vieira et al.(112) provided pre-treatment data (1-2 weeks after SAH and 2 weeks post-treatment). In qualification, it should be stated, that the unique results of Frazer et al.(29)(with superior functioning of MS patients) may have been influenced by preexisting group differences as to greater pre-morbid intelligence scores in the surgery group. A comparable limitation of our study, that cannot be disregarded, is the lack of data on premorbid intelligence scores and educational status. Due to the variability in educational level, Santiago-Ramajo et al.(99) repeated their study analyses, excluding the participants with less than 7 years of schooling, and obtained the same results.

The inconclusive findings may represent artifacts of incomplete recovery, especially when the neuropsychological outcome is assessed within 1 month after ictus $(55,71)$. The time delay of serial outcome evaluation between the acute stage of recovery and the late stages, approaching maximum recovery, might ensure the stability of cognitive profiles and increase the validity of neuropsychological outcome data.

\section{Impact of the Treatment Procedure on Neuropsychological Impairment}

Another factor that can intervene in the cognitive outcome of SAH patients may be the type of treatment applied. Several authors found no treatment-specific differences in cognition at 3 (55) and 4 months (99) after SAH, and similar QOL at 14 months (91), 1 year (90), and 24.5 years (107) after SAH. In our study, summary scores of the two surveys did not differ between the MS and the EV group, either. However, clipped patients reported better short-term Pfi, less Pain, and more alleviation in nutrition disorder than coiled patients.
The prolonged cephalgia in the EV group might be related to the longer persistence of blood in the basal cisterns compared to MS patients undergoing craniotomy, clipping, and intraoperative irrigation of subarachnoid blood. Agreeing with Frazer et al.(29), these findings could be interpreted that clipped patients experienced a greater initial decline in cognition from pre-morbid levels and, thus, had further ground to recover than coiled patients. By contrast, others suggested a more deleterious effect of MS compared to EV $(49,70,73,105)$, since they could show more cognitive impairment (depression, executive dysfunction, memory deficits) $(7,24,28,34)$ at least 1 year after surgery. Chan et al. (24) reasoned that, in clipped patients, the deficit might be attributed to an encoding deficit in contrast to a retrieval deficit in coiled patients.

Aneurysm management has been changing $(18,102)$ since the introduction (32) of EV in 1991 (32) and its ongoing technical refinement. Coiled patients scored better in neuropsychological measures in more recent years, which might in part be attributed to advances in endovascular techniques (25). In contrast, MS has been performed since the late 1930s, and the rate of advances in this procedure has slowed. Nowadays, EV has become a common method and oftentimes the initial treatment of choice for repair of intracranial aneurysms given its less invasive nature $(7,9,24,34,60,105)$. In contrast, clipping requires craniotomy, brain tissue retraction, and direct manipulation of arteries, which bears the risk of injury to perforating branches with consecutive reduction of blood flow $(21,24)$. The multicenter ISAT was the first and most comprehensive study, directly comparing the safety and efficacy of MS and EV techniques after aSAH with respect to differences in neurological morbidity and mortality rates (73), and in the N-ISAT, a substudy on the "Neuropsychological Outcomes from the ISAT", in neuropsychological outcome (105). The controversially discussed results deemed EV superior to MS with regard to lower risk of death and dependency at 1 year versus 2 months post-treatment (74). Cognitive impairment was more common in the MS group, and QOL was poorer in neuropsychologically disabled patients across both treatment modalities $(23,105)$. After the publication of this study, a series of studies with conflicting data complicated the discussion. The majority of authors $(7,29,55,91,99,103)$ disproved the hypothesis that the aneurysm-securing procedure poses an influencing factor on cognitive outcome after aSAH. Most recently, a valuable metaanalysis (25) systematically reviewed the literature $(7,24,26,28$, $34,55,58,59,89,91,99,112)$ on treatment-specific differences in cognitive outcome after aSAH and dismissed differences between both treatment approaches in most instances.

As highlighted by Egeto et al.(25), with 13 studies available, the comparative literature on treatment modality-dependent effects on cognitive processing after sSAH is sparse. Even fewer authors, like Koivisto et al.(55), have their patients randomly assigned to either MS or EV. Compared to a high volume center treating several aneurysms per day, with MS and EV of 150 patients per year our institution ranges in the middle field. Thus, our institutional neurovascular volume is representative for the majority of neurovascular centers. It has to be emphasized that a randomized study design would be 
preferable to our experimental trial to investigate the effects of treatment on cognitive processing. However, bounded by our annual patient volume and ethical considerations, a randomization in a medium-volume clinic on a single-center basis is hardly feasible. Thus, as described in the Material and Methods section, much effort has been made to analyze three homogeneous patient groups including a FU assessment for cognitive short-term and mid-term outcome. The basic characteristics of our cohort were comparable in all treatment groups in terms of gender, age, co-morbidities, severity of subarachnoid bleeding (27), and clinical grade (41). We caveat the statement with the note that our study is not powered to detect differences due to the small number. In a larger series, an additional power analysis of interactions between aneurysm location, treatment, and cognitive outcome is recommended. The presented groups are imbalanced in terms of a higher proportion of MCA aneurysms in favor of the surgical group, more antiplatelet drug intake at $t_{1}(E V)$ and a longer mean time spent on mechanical ventilatory support (pSAH). In adults, the time of anesthesia is extremely unlikely to influence cognitive performance, especially 6 months after treatment. Besides, all but one pSAH patient received intubation anesthesia for DSA, which allows the exclusion of general anesthesia as a negative confounding factor for the evaluation of post-treatment neurocognitive outcome. The predominance of MCA aneurysms could have a significant confounding effect on outcomes, given very different potential perforator injuries and extent of dissection required. From a microsurgical perspective, this fact seems to be negligible, as dominant-side and non-dominant-side pterional approaches were used equally ( $n=3$ each). In a larger sample size, these issues should be considered as a covariate in analysis to control for its impact.

MRI studies comparing brain structure damage consequent to MS or EV have rarely been reported. Several authors suggest more frontotemporal lesions after MS $(34,91)$. On the other hand, it is remarkable that silent thromboembolic events are a common finding after coiling despite meticulous technique and systemic anticoagulation. In this context, it is worth noting that (besides the patient's age, overall medical condition or presence of an intraparenchymal hemorrhage) aneurysm location and morphology are crucial in the selection of treatment type, thus introducing a bias. While most anterior communicating artery $(\mathrm{ACOA})$ aneurysm ruptures are eligible for either clipping or coiling, the angioanatomical features of MCA aneurysms (for example, adjacent arterial branches and small dome/neck ratios) usually constitute a contraindication for EV. As a consequence, studies with higher MCA rupture rates were, in some domains, associated with a more similar performance between clipped and coiled patients (25).

We would like to emphasize that MS and EV must not be considered as competing procedures but rather as two complementary methods for optimal aneurysm treatment. Our results underline that a collaborative interdisciplinary discourse between experienced interventional neuroradiologists and vascular neurosurgeons, integrated into a neurovascular team, is crucial for establishing the best and highly individualized therapeutic strategy with respect not only to aneurysm repair but also to the patient's ideal functional and neuropsychological outcome.

\section{Impact of the Bleeding Event Itself on Neuropsychological Impairment}

Our cohort comprises a reference group with PSAH patients, characterized by conservative management, to further illuminate the effect of the aneurysm treatment per se on cognitive and functional outcome. $10 \%$ of spontaneous bleeding events are non-aneurysmal perimesencephalic (63). Both aSAH and pSAH patients suffer from neuropsychological deficits after ictus $(14,52)$. In our series, the pSAH patients performed significantly better in various aspects of physical and psychological functioning at $t_{1}$ and $t_{2}$ than aSAH patients. In contrast to the treatment groups, our PSAH patients performed similar to healthy controls in most indices. Given our small sample size and the relatively short FU interval of 6 months, it has to be considered that subtle deficits in cognition and QOL after pSAH might not have been detected with the self-report measures applied. Contrary to former assumptions, which attested pSAH patients a favorable prognosis $(16,95)$, more recent findings $(64,65)$ indicated that pSAH might not be as benign as previously believed. On average 39 months after pSAH, survivors continued to suffer from cephalgia, depression, obliviousness, mild cognitive deficits and inability to resume their previous occupations $(64,65)$. In conclusion, the aneurysm-securing procedure alone does not sufficiently explain impaired neuropsychological outcome. The pathophysiology and origin of cognitive impairment after SAH is not completely understood (94). A growing body of evidence suggests that the severity of the hemorrhage $(7,42-44,49,52,81,82)$ and the consecutive combination of focal (66) and diffuse brain injury $(7,8,68,111)$ primarily cause the neuropsychological alterations after $\mathrm{SAH}$, rather than the aneurysm location or the selected treatment maneuver $(43,46,48,56,80,81)$.

In our trial, all sSAH groups, the pSAH patients alike, experienced a significant deterioration in Rawhtran. This fact might be attributed to the psychological traumatization by the event of bleeding itself $(5,11,76-78)$, especially in the short-term. The risk of developing chronic post-traumatic stress disorder (PTSD) (45) might depend on the traumatic event itself, since, for example, the risk for PTSD seems to be much lower after myocardial infarction than after SAH or mild head injury (106). Interestingly, there are systematic differences in selfand proxy-rated QOL with an under-reporting of symptoms and minimizing of complaints by the burdened patients (19). It is hypothesized that brain injury may weaken the patient's capacity to intentionally suppress intrusive thoughts leading to increased avoidance or to undue unconcern, neglect or unawareness of symptoms (19). We argue that this fact should be considered when evaluating cognition, in particular in selfreport assessments. In our study design, however, confounders seem to be minimized by the selection of good-grade SAH patients and by the information given in the semi-structured interview.

\section{Methodological Considerations}

Limits: The small sample size is a commonly acknowledged 
methodological limitation, which may tremendously affect the results. However, we preferred analyzing homogeneous groups to recruiting a larger but inhomogeneous cohort, which might be susceptible to misinterpretations. The strict and very detailed selection criteria were set up to minimize confounding variables and to maximize the generalizability by generating valid and robust data.

A caveat to our findings is the typically reported selection bias by the overrepresentation of "ideal" SAH patients with good neurological status on admission. This degree of collective homogeneity may limit potential test performance differences. Furthermore, our results, reflecting the best condition attainable, are probably not applicable to poor-grade SAH patients. In almost all SAH trials on treatment-dependent cognitive outcome $(7,24,26,28,29,34,55,58,59,89,99,112)$, the majority of patients enrolled initially presented with a good clinical grade (25). Solely, Proust et al.(91) published a collective with a higher proportion of $\mathrm{HH}$ grade III-IV cases. From a methodological point of view, a major reason for the omission of poor-grade SAH individuals is the assumable inability or unwillingness to undergo a demanding neuropsychological test battery. Moreover, only 21/26 recruited patients could be assessed cognitively at FU. One may speculate that the 5 excluded patients were unable to complete the cognitive assessment due to severe neuropsychological impairment, and, hence, the true impairment rate was underestimated.

Instead of a performance-based neuropsychological assessment, this study is based on self-report measures, which might not be sensitive and comprehensive enough to detect all impaired patients, and which do not systematically cover all relevant cognitive domains. However, subjective experience of neuropsychological dysfunction is considerable from a QOL perspective. In addition, the error rate due to potential fatigue in lengthy, comprehensive and demanding cognitive batteries might be minimized. Rapid and sensitive bedside screening tools like the SF-36 and the ISR can be used to identify candidates for detailed neuropsychological assessment.

Early outcome evaluation at acute stages bears the risk of detecting transient and non-final differing negative effects of aneurysm treatment on cognitive performance, leveling off or even worsening over time, or the risk of measuring the impact of the bleeding itself rather than treatment-associated phenomena. FU testing in neuropsychological outcome assessment is scarce $(29,55)$. Thus, our trial contributes valuable data to the time course of neuropsychological performance in the early stages of recovery. Both mediumterm and long-term outcome assessments in the setting of (randomized) multicenter trials like the Swiss "Study on Aneurysmal Subarachnoid Hemorrhage" (SOS) study group (121) are required to verify the severity of cognitive impairment and follow the course of neuropsychological changes in individual patients over years.

Strengths: Compared to the limited number of SAH trials dealing with the effects of aneurysm treatment on cognition, the actual strength of this study lies in its prospective and standardized design with an accurate evaluation of functional outcome, QOL, and neurobehavioral dysfunction after SSAH. This is the first study examining SAH patients by means of the ISR. The questionnaire is validated in psychosomatic disorders and can be recommended in the evaluation of neuropsychological sequelae in SAH patients for the future. Eminently, the inclusion of a reference group with pSAH provided further information to what extent aneurysmsecuring procedures per se affect cognitive outcome.

\section{CONCLUSION}

We investigated the treatment-specific differences in the time course of neuropsychological recovery within the first 6 months after SSAH. Our preliminary data on self-reported QOL, and physical and mental well-being after treatment for aSAH indicates that, in the short-term, there are minimal differences between MS and EV for ruptured intracranial aneurysms with a significantly better performance in Pfi, more alleviation in nutrition disorder, and less Pain in surgically treated patients compared to their coiled counterparts. However, the treatment modality does not seem to affect overall neuropsychological outcome, at least at 6 month-FU. Both the MS and EV patients improved in several physical items over time. Yet, the EV patients still performed significantly worse in Pfi, Rolph, Mhi, and, together with the MS patients, in Vital, than healthy controls. Thus, we argue that, from a QOL perspective, MS patients may recover at a faster rate in the short-term after aSAH. pSAH patients performed significantly better in various aspects of physical and psychological functioning than patients with aSAH at $t_{1}$ and $t_{2}$. The deficiency of studies dealing with this issue prevents any strong conclusions, although a few recent studies yielded similar results. Prospective randomized trials are mandatory to elucidate the treatmentassociated neuropsychological morbidity in the long-run and to advise individualized future care management strategies and physical, neurological, cognitive, and occupational rehabilitation approaches.

\section{REFERENCES}

1. [No authors listed]: Report of World Federation of Neurological Surgeons Committee on a Universal Subarachnoid Hemorrhage Grading Scale. J Neurosurg 68: 985-986, 1988

2. Ahola K, Vilkki J, Servo A: Frontal tests do not detect frontal infarctions after ruptured intracranial aneurysm. Brain Cogn 31: 1-16, 1996

3. Al-Khindi T, Macdonald RL, Schweizer TA: Cognitive and functional outcome after aneurysmal subarachnoid hemorrhage. Stroke 41: e519-536, 2010

4. Ardila A: Directions of research in cross-cultural neuropsychology. J Clin Exp Neuropsychol 17: 143-150, 1995

5. Baisch SB, Schenk T, Noble AJ: What is the cause of post-traumatic stress disorder following subarachnoid haemorrhage? Post-ictal events are key. Acta Neurochir (Wien) 153: 913-922, 2011 
6. Bederson JB, Connolly ES Jr, Batjer HH, Dacey RG, Dion $\mathrm{JE}$, Diringer MN, Duldner JE Jr, Harbaugh RE, Patel $A B$, Rosenwasser $\mathrm{RH}$, American Heart $\mathrm{A}$ : Guidelines for the management of aneurysmal subarachnoid hemorrhage: $A$ statement for healthcare professionals from a special writing group of the Stroke Council, American Heart Association. Stroke 40: 994-1025, 2009

7. Bellebaum C, Schafers L, Schoch B, Wanke I, Stolke D, Forsting M, Daum I: Clipping versus coiling: Neuropsychological follow up after aneurysmal subarachnoid haemorrhage (SAH). J Clin Exp Neuropsychol 26:1081-1092, 2004

8. Bendel $\mathrm{P}$, Koivisto $\mathrm{T}$, Aikia $\mathrm{M}$, Niskanen $\mathrm{E}$, Kononen $\mathrm{M}$, Hanninen T, Vanninen R: Atrophic enlargement of CSF volume after subarachnoid hemorrhage: Correlation with neuropsychological outcome. AJNR Am J Neuroradiol 31: 370-376, 2010

9. Benes V 3rd, Mitchell P, Molyneux AJ, Renowden SA: Endovascular coiling in 131 patients with low complication rate justifies treating most unruptured intracranial aneurysms. Cent Eur Neurosurg 71: 1-7, 2010

10. Benke T, Koylu B, Delazer M, Trinka E, Kemmler G: Cholinergic treatment of amnesia following basal forebrain lesion due to aneurysm rupture-an open-label pilot study. Eur J Neurol 12: 791-796, 2005

11. Berry E: Post-traumatic stress disorder after subarachnoid haemorrhage. Br J Clin Psychol 37 (Pt 3): 365-367, 1998

12. Berry E, Jones RA, West CG, Brown JD: Outcome of subarachnoid haemorrhage. An analysis of surgical variables, cognitive and emotional sequelae related to SPECT scanning. Br J Neurosurg 11: 378-387, 1997

13. Bjeljac M, Keller E, Regard M, Yonekawa Y: Neurological and neuropsychological outcome after SAH. Acta Neurochir Suppl 82: 83-85, 2002

14. Boerboom W, Heijenbrok-Kal MH, Khajeh L, van Kooten F, Ribbers GM: Differences in cognitive and emotional outcomes between patients with perimesencephalic and aneurysmal subarachnoid haemorrhage. J Rehabil Med 46: 28-32, 2014

15. Boerboom W, Jacobs EA, Khajeh L, van Kooten F, Ribbers GM, Heijenbrok-Kal MH: The relationship of coping style with depression, burden, and life dissatisfaction in caregivers of patients with subarachnoid haemorrhage. J Rehabil Med 46: 321-326, 2014

16. Brilstra EH, Hop JW, Rinkel GJ: Quality of life after perimesencephalic haemorrhage. J Neurol Neurosurg Psychiatry 63: 382-384, 1997

17. Brundl E, Bohm C, Lurding R, Schodel P, Bele S, Hochreiter A, Scheitzach J, Zeman F, Brawanski A, Schebesch KM: Treatment of unruptured intracranial aneurysms and cognitive performance: Preliminary results of a prospective clinical trial. World Neurosurg 94: 145-156, 2016

18. Bryan RN, Rigamonti D, Mathis JM: The treatment of acutely ruptured cerebral aneurysms: Endovascular therapy versus surgery. AJNR Am J Neuroradiol 18: 1826-1830, 1997

19. Bryant RA: Posttraumatic stress disorder and mild brain injury: Controversies, causes and consequences. J Clin Exp Neuropsychol 23: 718-728, 2001
20. Bullinger M: German translation and psychometric testing of the SF-36 Health Survey: Preliminary results from the IQOLA Project. International Quality of Life Assessment. Soc Sci Med 41: 1359-1366, 1995

21. Camuscu H, Dujovny M, Abd el-Bary T, Beristain X, Vinas FC: Microanatomy of the perforators of the anterior communicating artery complex. Neurol Res 19: 577-587, 1997

22. Carter BS, Buckley D, Ferraro R, Rordorf G, Ogilvy CS: Factors associated with reintegration to normal living after subarachnoid hemorrhage. Neurosurgery 46: 1326-1333; discussion 1333-1334, 2000

23. Chahal N, Barker-Collo S, Feigin V: Cognitive and functional outcomes of 5-year subarachnoid haemorrhage survivors: Comparison to matched healthy controls. Neuroepidemiology 37: 31-38, 2011

24. Chan A, Ho S, Poon WS: Neuropsychological sequelae of patients treated with microsurgical clipping or endovascular embolization for anterior communicating artery aneurysm. Eur Neurol 47: 37-44, 2002

25. Egeto P, Loch Macdonald R, Ornstein TJ, Schweizer TA: Neuropsychological function after endovascular and neurosurgical treatment of subarachnoid hemorrhage: $A$ systematic review and meta-analysis. J Neurosurg 1-9, 2017 (Epub ahead of print)

26. Escartin G, Junque C, Juncadella M, Gabarros A, de Miquel MA, Rubio F: Decision-making impairment on the lowa Gambling Task after endovascular coiling or neurosurgical clipping for ruptured anterior communicating artery aneurysm. Neuropsychology 26: 172-180, 2012

27. Fisher CM, Kistler JP, Davis JM: Relation of cerebral vasospasm to subarachnoid hemorrhage visualized by computerized tomographic scanning. Neurosurgery 6: 1-9, 1980

28. Fontanella M, Perozzo P, Ursone R, Garbossa D, Bergui M: Neuropsychological assessment after microsurgical clipping or endovascular treatment for anterior communicating artery aneurysm. Acta Neurochir (Wien) 145: 867-872; discussion 872, 2003

29. Frazer D, Ahuja A, Watkins L, Cipolotti L: Coiling versus clipping for the treatment of aneurysmal subarachnoid hemorrhage: A longitudinal investigation into cognitive outcome. Neurosurgery 60: 434-441; discussion 441-442, 2007

30. Fukunaga A, Uchida K, Hashimoto J, Kawase $\mathrm{T}$ : Neuropsychological evaluation and cerebral blood flow study of 30 patients with unruptured cerebral aneurysms before and after surgery. Surg Neurol 51: 132-139, 1999

31. Fung C, Beck J, Lauber L, Muri R, Raabe A, Nyffeler T: Clinical assessment of deficits after SAH: Hasty neurosurgeons and accurate neurologists. J Neurol 259: 2198-2201, 2012

32. Guglielmi G, VinuelaF, SepetkaI, Macellari V: Electrothrombosis of saccular aneurysms via endovascular approach. Part 1: Electrochemical basis, technique, and experimental results. J Neurosurg 75: 1-7, 1991

33. Hackett ML, Anderson CS: Health outcomes 1 year after subarachnoid hemorrhage: An international population-based study. The Australian Cooperative Research on Subarachnoid Hemorrhage Study Group. Neurology 55: 658-662, 2000 
34. Hadjivassiliou M, Tooth CL, Romanowski CA, Byrne J, Battersby RD, Oxbury S, Crewswell CS, Burkitt E, Stokes NA, Paul C, Mayes AR, Sagar HJ: Aneurysmal SAH: Cognitive outcome and structural damage after clipping or coiling. Neurology 56: 1672-1677, 2001

35. Hanggi D, Eicker S, Beseoglu K, Behr J, Turowski B, Steiger $\mathrm{HJ}$ : A multimodal concept in patients after severe aneurysmal subarachnoid hemorrhage: Results of a controlled single centre prospective randomized multimodal phase I/II trial on cerebral vasospasm. Cent Eur Neurosurg 70: 61-67, 2009

36. Haug T, Sorteberg A, Finset A, Lindegaard KF, Lundar T, Sorteberg W: Cognitive functioning and health-related quality of life 1 year after aneurysmal subarachnoid hemorrhage in preoperative comatose patients (Hunt and Hess Grade V patients). Neurosurgery 66: 475-484; discussion 484-485, 2010

37. Haug T, Sorteberg A, Sorteberg W, Lindegaard KF, Lundar T, Finset A: Cognitive outcome after aneurysmal subarachnoid hemorrhage: Time course of recovery and relationship to clinical, radiological, and management parameters. Neurosurgery 60: 649-656; discussion 656-657, 2007

38. Hillis AE, Anderson N, Sampath P, Rigamonti D: Cognitive impairments after surgical repair of ruptured and unruptured aneurysms. J Neurol Neurosurg Psychiatry 69: 608-615, 2000

39. Hop JW, Rinkel GJ, Algra A, van Gijn J: Quality of life in patients and partners after aneurysmal subarachnoid hemorrhage. Stroke 29: 798-804, 1998

40. Hop JW, Rinkel GJ, Algra A, van Gijn J: Changes in functional outcome and quality of life in patients and caregivers after aneurysmal subarachnoid hemorrhage. J Neurosurg 95: 957963, 2001

41. Hunt WE, Hess RM: Surgical risk as related to time of intervention in the repair of intracranial aneurysms. J Neurosurg 28: 14-20, 1968

42. Hutter BO: Psychologic adjustment in patients after subarachnoid hemorrhage. Neuropsychiatry Neuropsychol Behav Neurol 11: 22-30, 1998

43. Hutter BO, Gilsbach JM: Which neuropsychological deficits are hidden behind a good outcome (Glasgow = I) after aneurysmal subarachnoid hemorrhage? Neurosurgery 33: 999-1005; discussion 1005-1006, 1993

44. Hutter BO, Gilsbach JM, Kreitschmann I: Quality of life and cognitive deficits after subarachnoid haemorrhage. $\mathrm{Br} J$ Neurosurg 9: 465-475, 1995

45. Hutter BO, Kreitschmann-Andermahr I: Subarachnoid hemorrhage as a psychological trauma. J Neurosurg 120: 923-930, 2014

46. Hutter BO, Kreitschmann-Andermahr I, Gilsbach JM: Cognitive deficits in the acute stage after subarachnoid hemorrhage. Neurosurgery 43: 1054-1065, 1998

47. Hutter BO, Kreitschmann-Andermahr I, Gilsbach JM: Health-related quality of life after aneurysmal subarachnoid hemorrhage: Impacts of bleeding severity, computerized tomography findings, surgery, vasospasm, and neurological grade. J Neurosurg 94: 241-251, 2001
48. Hutter BO, Kreitschmann-Andermahr I, Mayfrank L, Rohde V, Spetzger U, Gilsbach JM: Functional outcome after aneurysmal subarachnoid hemorrhage. Acta Neurochir Suppl 72: 157-174, 1999

49. Jaja BN, Cusimano MD, Etminan N, Hanggi D, Hasan D, llodigwe $D$, Lantigua $H$, Le Roux P, Lo B, Louffat-Olivares A, Mayer S, Molyneux A, Quinn A, Schweizer TA, Schenk T, Spears J, Todd M, Torner J, Vergouwen MD, Wong GK, Singh J, Macdonald RL: Clinical prediction models for aneurysmal subarachnoid hemorrhage: A systematic review. Neurocrit Care 18: 143-153, 2013

50. Jennett B, Bond M: Assessment of outcome after severe brain damage. Lancet 1: 480-484, 1975

51. Kagerbauer SM, Kemptner DM, Schepp CP, Bele S, Rothorl $\mathrm{RD}$, Brawanski AT, Schebesch KM: Elevated premorbid body mass index is not associated with poor neurological outcome in the subacute state after aneurysmal subarachnoid hemorrhage. Cent Eur Neurosurg 71: 163-166, 2010

52. Kapadia A, Schweizer TA, Spears J, Cusimano M, Macdonald RL: Nonaneurysmal perimesencephalic subarachnoid hemorrhage: Diagnosis, pathophysiology, clinical characteristics, and long-term outcome. World Neurosurg 82: 1131-1143, 2014

53. Katati MJ, Santiago-Ramajo S, Perez-Garcia M, MeersmansSanchez Jofre M, Vilar-Lopez R, Coin-Mejias MA, CaracuelRomero A, Arjona-Moron V: Description of quality of life and its predictors in patients with aneurysmal subarachnoid hemorrhage. Cerebrovasc Dis 24: 66-73, 2007

54. Kim DH, Haney CL, Van Ginhoven G: Utility of outcome measures after treatment for intracranial aneurysms: A prospective trial involving 520 patients. Stroke 36: 792-796, 2005

55. Koivisto T, Vanninen R, Hurskainen H, Saari T, Hernesniemi J, Vapalahti M: Outcomes of early endovascular versus surgical treatment of ruptured cerebral aneurysms. A prospective randomized study. Stroke 31: 2369-2377, 2000

56. Kreiter KT, Copeland D, Bernardini GL, Bates JE, Peery S, Claassen J, Du YE, Stern Y, Connolly ES, Mayer SA: Predictors of cognitive dysfunction after subarachnoid hemorrhage. Stroke 33: 200-208, 2002

57. Kutlubaev MA, Barugh AJ, Mead GE: Fatigue after subarachnoid haemorrhage: A systematic review. J Psychosom Res 72: 305-310, 2012

58. Ladowski D, Qian W, Kapadia AN, Macdonald RL, Schweizer TA: Effect of aneurysmal subarachnoid hemorrhage on word generation. Behav Neurol 2014: 610868, 2014

59. Latimer SF, Wilson FC, McCusker CG, Caldwell SB, Rennie I: Subarachnoid haemorrhage (SAH): Long-term cognitive outcome in patients treated with surgical clipping or endovascular coiling. Disabil Rehabil 35: 845-850, 2013

60. Li H, Pan R, Wang H, Rong X, Yin Z, Milgrom DP, Shi X, Tang $Y$, Peng Y: Clipping versus coiling for ruptured intracranial aneurysms: A systematic review and meta-analysis. Stroke 44: 29-37, 2013

61. Ljunggren B, Sonesson B, Saveland H, Brandt L: Cognitive impairment and adjustment in patients without neurological deficits after aneurysmal SAH and early operation. J Neurosurg 62: 673-679, 1985 
62. Macdonald RL, Cusimano MD, Etminan N, Hanggi D, Hasan D, llodigwe D, Jaja B, Lantigua H, Le Roux P, Lo B, LouffatOlivares A, Mayer S, Molyneux A, Quinn A, Schweizer TA, Schenk T, Spears J, Todd M, Torner J, Vergouwen MD, Wong GK, Collaboration S: Subarachnoid Hemorrhage International Trialists data repository (SAHIT). World Neurosurg 79: 418422, 2013

63. Macdonald RL, Schweizer TA: Spontaneous subarachnoid haemorrhage. Lancet 389: 655-666, 2017

64. Madureira S, Canhao P, Guerreiro M, Ferro JM: Cognitive and emotional consequences of perimesencephalic subarachnoid hemorrhage. J Neurol 247: 862-867, 2000

65. Marquardt G, Niebauer T, Schick U, Lorenz R: Long term follow up after perimesencephalic subarachnoid haemorrhage. J Neurol Neurosurg Psychiatry 69: 127-130, 2000

66. Martinaud O, Perin B, Gerardin E, Proust F, Bioux S, Gars DL, Hannequin D, Godefroy O: Anatomy of executive deficit following ruptured anterior communicating artery aneurysm. Eur J Neurol 16: 595-601, 2009

67. Maurice-Williams RS, Willison JR, Hatfield R: The cognitive and psychological sequelae of uncomplicated aneurysm surgery. J Neurol Neurosurg Psychiatry 54: 335-340, 1991

68. Mavaddat N, Sahakian BJ, Hutchinson PJ, Kirkpatrick PJ: Cognition following subarachnoid hemorrhage from anterior communicating artery aneurysm: Relation to timing of surgery. J Neurosurg 91: 402-407, 1999

69. Mayer SA, Kreiter KT, Copeland D, Bernardini GL, Bates JE, Peery S, Claassen J, Du YE, Connolly ES Jr: Global and domain-specific cognitive impairment and outcome after subarachnoid hemorrhage. Neurology 59: 1750-1758, 2002

70. McDougall CG, Spetzler RF, Zabramski JM, Partovi S, Hills NK, Nakaji P, Albuquerque FC: The barrow ruptured aneurysm trial. J Neurosurg 116: 135-144, 2012

71. McKenna P, Willison JR, Phil B, Lowe D, Neil-Dwyer G: Cognitive outcome and quality of life one year after subarachnoid haemorrhage. Neurosurgery 24: 361-367, 1989

72. Meyer B, Ringel F, Winter Y, Spottke A, Gharevi N, Dams J, Balzer-Geldsetzer M, Mueller IK, Klockgether T, Schramm J, Urbach H, Dodel R: Health-related quality of life in patients with subarachnoid haemorrhage. Cerebrovasc Dis 30: 423431, 2010

73. Molyneux A, Kerr R, Stratton I, Sandercock P, Clarke M, Shrimpton J, Holman R; International Subarachnoid Aneurysm Trial Collaborative G: International Subarachnoid Aneurysm Trial (ISAT) of neurosurgical clipping versus endovascular coiling in 2143 patients with ruptured intracranial aneurysms: A randomised trial. Lancet 360: 1267-1274, 2002

74. Molyneux AJ, Kerr RS, Yu LM, Clarke M, Sneade M, Yarnold JA, Sandercock P; International Subarachnoid Aneurysm Trial Collaborative G: International subarachnoid aneurysm trial (ISAT) of neurosurgical clipping versus endovascular coiling in 2143 patients with ruptured intracranial aneurysms: A randomised comparison of effects on survival, dependency, seizures, rebleeding, subgroups, and aneurysm occlusion. Lancet 366: 809-817, 2005
75. Nieuwkamp DJ, Setz LE, Algra A, Linn FH, de Rooij NK, Rinkel GJ: Changes in case fatality of aneurysmal subarachnoid haemorrhage over time, according to age, sex, and region: $A$ meta-analysis. Lancet Neurol 8: 635-642, 2009

76. Noble AJ, Baisch S, Covey J, Mukerji N, Nath F, Schenk T: Subarachnoid hemorrhage patients' fears of recurrence are related to the presence of posttraumatic stress disorder. Neurosurgery 69: 323-332; discussion 332-333, 2011

77. Noble AJ, Baisch S, Mendelow AD, Allen L, Kane P, Schenk T: Posttraumatic stress disorder explains reduced quality of life in subarachnoid hemorrhage patients in both the short and long term. Neurosurgery 63: 1095-1104; discussion 10041005, 2008

78. Noble AJ, Schenk T: Which variables help explain the poor health-related quality of life after subarachnoid hemorrhage? A meta-analysis. Neurosurgery 66: 772-783, 2010

79. Nolte S, Mierke A, Fischer HF, Rose M: On the validity of measuring change over time in routine clinical assessment: A close examination of item-level response shifts in psychosomatic inpatients. Qual Life Res 25: 1339-1347, 2016

80. Oder W, Kollegger H, Zeiler K, Dal-Bianco P, Wessely P, Deecke L: Subarachnoid hemorrhage of unknown etiology: Early prognostic factors for long-term functional capacity. J Neurosurg 74: 601-605, 1991

81. Ogden JA, Mee EW, Henning M: A prospective study of impairment of cognition and memory and recovery after subarachnoid hemorrhage. Neurosurgery 33: 572-586; discussion 586-587, 1993

82. Ogden JA, Utley T, Mee EW: Neurological and psychosocial outcome 4 to 7 years after subarachnoid hemorrhage. Neurosurgery 41: 25-34, 1997

83. Orbo $M$, Waterloo $\mathrm{K}$, Egge $\mathrm{A}$, Isaksen $\mathrm{J}$, Ingebrigtsen $\mathrm{T}$, Romner B: Predictors for cognitive impairment one year after surgery for aneurysmal subarachnoid hemorrhage. J Neurol 255: 1770-1776, 2008

84. Passier PE, Post MW, van Zandvoort MJ, Rinkel GJ, Lindeman E, Visser-Meily JM: Predicting fatigue 1 year after aneurysmal subarachnoid hemorrhage. J Neurol 258: 1091-1097, 2011

85. Passier PE, Visser-Meily JM, van Zandvoort MJ, Post MW, Rinkel GJ, van Heugten C: Prevalence and determinants of cognitive complaints after aneurysmal subarachnoid hemorrhage. Cerebrovasc Dis 29: 557-563, 2010

86. Powell J, Kitchen N, Heslin J, Greenwood R: Psychosocial outcomes at three and nine months after good neurological recovery from aneurysmal subarachnoid haemorrhage: Predictors and prognosis. J Neurol Neurosurg Psychiatry 72: 772-781, 2002

87. Powell J, Kitchen N, Heslin J, Greenwood R: Psychosocial outcomes at 18 months after good neurological recovery from aneurysmal subarachnoid haemorrhage. J Neurol Neurosurg Psychiatry 75: 1119-1124, 2004

88. Preiss M, Koblihova J, Netuka D, Bernardova L, Charvat F, Benes V: Verbal memory capacity after treatment for ruptured intracranial aneurysm--the outcomes of three psychological tests: Within a month, 1 year after and 5-7 years after treatment. Acta Neurochir (Wien) 154: 417-422, 2012 
89. Preiss M, Koblihova J, Netuka D, Klose J, Charvat F, Benes V: Ruptured cerebral aneurysm patients treated by clipping or coiling: Comparison of long-term neuropsychological and personality outcomes. Zentralbl Neurochir 68: 169-175, 2007

90. Preiss M, Netuka D, Koblihova J, Bernardova L, Charvat F, Kratochvilova D, Benes V: Quality of life 1 year after aneurysmal subarachnoid hemorrhage in good outcome patients treated by clipping or coiling. J Neurol Surg A Cent Eur Neurosurg 73: 217-223, 2012

91. Proust F, Martinaud O, Gerardin E, Derrey S, Leveque S, Bioux S, Tollard E, Clavier E, Langlois O, Godefroy O, Hannequin D, Freger P: Quality of life and brain damage after microsurgical clip occlusion or endovascular coil embolization for ruptured anterior communicating artery aneurysms: Neuropsychological assessment. J Neurosurg 110: 19-29, 2009

92. Rankin J: Cerebral vascular accidents in patients over the age of 60. II. Prognosis. Scott Med J 2: 200-215, 1957

93. Richardson JT: Cognitive performance following rupture and repair of intracranial aneurysm. Acta Neurol Scand 83: 110122, 1991

94. Rinkel GJ, Algra A: Long-term outcomes of patients with aneurysmal subarachnoid haemorrhage. Lancet Neurol 10: 349-356, 2011

95. Rinkel GJ, Wijdicks EF, Vermeulen M, Hageman LM, Tans JT, van Gijn J: Outcome in perimesencephalic (nonaneurysmal) subarachnoid hemorrhage: A follow-up study in 37 patients. Neurology 40: 1130-1132, 1990

96. Ronne-Engstrom E, Enblad P, Lundstrom E: Outcome after spontaneous subarachnoid hemorrhage measured with the EQ-5D. Stroke 42: 3284-3286, 2011

97. Ropper AH, Zervas NT: Outcome 1 year after SAH from cerebral aneurysm. Management morbidity, mortality, and functional status in 112 consecutive good-risk patients. J Neurosurg 60: 909-915, 1984

98. Rosselli M, Ardila A: The impact of culture and education on non-verbal neuropsychological measurements: A critical review. Brain Cogn 52: 326-333, 2003

99. Santiago-Ramajo S, Katati MJ, Perez-Garcia M, Coin-Mejias MA, Vilar-Lopez R, Caracuel-Romero A, Arjona-Moron V: Neuropsychological evaluation of the treatments applied to intracranial aneurysms in a Spanish sample. J Clin Exp Neuropsychol 29: 634-641, 2007

100. Saveland H, Sonesson B, Ljunggren B, Brandt L, Uski T, Zygmunt S, Hindfelt B: Outcome evaluation following subarachnoid hemorrhage. J Neurosurg 64: 191-196, 1986

101. Scharbrodt W, Stein M, Schreiber V, Boker DK, Oertel MF: The prediction of long-term outcome after subarachnoid hemorrhage as measured by the Short Form-36 Health Survey. J Clin Neurosci 16: 1409-1413, 2009

102. Schievink WI: Intracranial aneurysms. N Engl J Med 336: 2840, 1997

103. Schuiling WJ, Rinkel GJ, Walchenbach R, de Weerd AW: Disorders of sleep and wake in patients after subarachnoid hemorrhage. Stroke 36: 578-582, 2005
104. Schwartz C, Pfefferkorn T, Ebrahimi C, Ottomeyer C, Fesl G, Bender A, Straube A, Pfister HW, Heck S, Tonn JC, Schichor C: Long-term neurological outcome and quality of life after World Federation of Neurosurgical Societies Grades IV and V aneurysmal subarachnoid hemorrhage in an interdisciplinary treatment concept. Neurosurgery 80: 967-974, 2017

105. Scott RB, Eccles F, Molyneux AJ, Kerr RS, Rothwell PM, Carpenter K: Improved cognitive outcomes with endovascular coiling of ruptured intracranial aneurysms: Neuropsychological outcomes from the International Subarachnoid Aneurysm Trial (ISAT). Stroke 41: 1743-1747, 2010

106. Sheldrick R, Tarrier N, Berry E, Kincey J: Post-traumatic stress disorder and illness perceptions over time following myocardial infarction and subarachnoid haemorrhage. $\mathrm{Br} J$ Health Psychol 11: 387-400, 2006

107. Sonesson B, Kronvall E, Saveland H, Brandt L, Nilsson OG: Long-term reintegration and quality of life in patients with subarachnoid hemorrhage and a good neurological outcome: Findings after more than 20 years. J Neurosurg 128(3):785-792, 2018

108. Stabell KE, Magnaes B: Neuropsychological course after surgery for intracranial aneurysms. A prospective study and a critical review. Scand J Psychol 38: 127-137, 1997

109. Teasdale GM, Drake CG, Hunt W, Kassell N, Sano K, Pertuiset B, De Villiers JC: A universal subarachnoid hemorrhage scale: Report of a committee of the World Federation of Neurosurgical Societies. J Neurol Neurosurg Psychiatry 51: 1457, 1988

110. Tritt K, von Heymann F, Zaudig M, Zacharias I, Sollner W, Loew T: Development of the "ICD-10-Symptom-Rating"(ISR) questionnaire. Z Psychosom Med Psychother 54: 409-418, 2008 (In German)

111. Uski TK, Lilja A, Saveland H, Ekman R, Sonesson $B$, Brandt L: Cognitive functioning and cerebrospinal fluid concentrations of neuropeptides for patients with good neurological outcomes after aneurysmal subarachnoid hemorrhage. Neurosurgery 47: 812-818, 2000

112. Vieira AC, Azevedo-Filho HR, Andrade G, Costa e Silva IE, de Fatima Leal Griz M, Quinino S, Leitao L, Souza ML, Camara D Jr: Cognitive changes in patients with aneurysmal subarachnoid hemorrhage before and early posttreatment: Differences between surgical and endovascular. World Neurosurg 78: 95-100, 2012

113. Vilkki J, Holst P, Ohman J, Servo A, Heiskanen O: Social outcome related to cognitive performance and computed tomographic findings after surgery for a ruptured intracranial aneurysm. Neurosurgery 26: 579-584; discussion 584-585, 1990

114. Visser-Meily JM, Rhebergen ML, Rinkel GJ, van Zandvoort MJ, Post MW: Long-term health-related quality of life after aneurysmal subarachnoid hemorrhage: Relationship with psychological symptoms and personality characteristics. Stroke 40: 1526-1529, 2009

115. von Vogelsang AC, Burstrom K, Wengstrom $Y$, Svensson M, Forsberg C: Health-related quality of life 10 years after intracranial aneurysm rupture: A retrospective cohort study using EQ-5D. Neurosurgery 72: 397-405; discussion 405406,2013 
116. Ware JE, Snow KK, Kosinski M, Gandek B: SF-36 Health Survey: Manual and interpretation guide. Boston, MA: Health Institute, New England Medical Center, 1993

117. Wermer MJ, Kool H, Albrecht KW, Rinkel GJ; Aneurysm Screening after Treatment for Ruptured Aneurysms Study G: Subarachnoid hemorrhage treated with clipping: Longterm effects on employment, relationships, personality, and mood. Neurosurgery 60: 91-97; discussion 97-98, 2007

118. Woitzik J, Dreier JP, Hecht N, Fiss I, Sandow N, Major S, Winkler M, Dahlem YA, Manville J, Diepers M, Muench E, Kasuya H, Schmiedek P, Vajkoczy P; Group Cs: Delayed cerebral ischemia and spreading depolarization in absence of angiographic vasospasm after subarachnoid hemorrhage. J Cereb Blood Flow Metab 32: 203-212, 2012

119. Wong GK, Lam S, Ngai K, Wong A, Mok V, Poon WS; Cognitive Dysfunction after Aneurysmal Subarachnoid Haemorrhage I: Evaluation of cognitive impairment by the Montreal cognitive assessment in patients with aneurysmal subarachnoid haemorrhage: Prevalence, risk factors and correlations with 3 month outcomes. J Neurol Neurosurg Psychiatry 83: 1112-1117, 2012
120. Wong GK, Poon WS, Boet R, Chan MT, Gin T, Ng SC, Zee BC: Health-related quality of life after aneurysmal subarachnoid hemorrhage: Profile and clinical factors. Neurosurgery 68: 1556-1561; discussion 1561, 2011

121. Zweifel-Zehnder AE, Stienen MN, Chicherio C, StuderusGermann A, Blasi S, Rossi S, Gutbrod K, Schmid N, Beaud V, Mondadori C, Brugger P, Sacco L, Muri R, Hildebrandt G, Fournier JY, Keller E, Regli L, Fandino J, Mariani L, Raabe A, Daniel RT, Reinert M, Robert T, Schatlo B, Bijlenga P, Schaller K, Monsch AU; Swiss SOSsg: Call for uniform neuropsychological assessment after aneurysmal subarachnoid hemorrhage: Swiss recommendations. Acta Neurochir (Wien) 157: 1449-1458, 2015 